\title{
Thermodynamics of Formation of Porous Polymeric Membrane by Phase Separation Method III. Pore Formation by Contacting Secondary Particles: Theory and Its Comparison with Experiments
}

\author{
Hideki IIJIma, Shigenobu Matsuda, and Kenji KamidE* \\ Fundamental Research Laboratory of Natural \& Synthetic Polymers, \\ Asahi Chemical Industry Co., Ltd., \\ 11-7 Hacchonawate, Takatsuki, Osaka 569, Japan \\ * Laboratory of Clothing, Faculty of Education, Kumamoto University, \\ Kurokami 2-40-1, Kumamoto 860, Japan
}

(Received August 2, 1993)

\begin{abstract}
An attempt was made (1) to establish a theory of pore characteristics, including pore size distribution $N(r)$ ( $r$, radius of pore) for porous polymeric membranes, prepared by the phase separation method, using two-phase volume ratio $R\left(\equiv V_{(1)} / V_{(2)} ; V_{(1)}\right.$ and $V_{(2)}$ are volumes of polymer-lean and -rich phases, respectively) and radius of secondary particle $S_{2}$ and (2) to compare the $N(r)$ calculated from $R$ and $S_{2}$ with that by an electron micrographic (EM) method. For this purpose, we assume that secondary particles (i.e., polymer-rich phase) and hypothetical vacant particles (i.e., polymer-lean phase) are placed randomly on a hexagonal closest packing lattice and that $x$ vacant particles contact with each other to form a pore (referred to as vacant-particle pore). An expression of the probability $P(x)$ that a given pore contains $x$ vacant particles was derived. With consideration of an increase in pore size after drying, $N(r)$ for vacant-particle pores, $N_{\mathrm{v}}(r)$ was derived, using $R, S_{2}$ and pore density of vacant-particle pores $N_{\mathrm{P}}$ (number $/ \mathrm{m}^{2}$ ), and by translating $x$ to pore radius $r$. The condition of determining $N_{\mathrm{P}}$ from $R$ and $S_{2}$ was established. $N(r)$ for inter-polymer-particle pores, $N_{\mathrm{i}}(r)$ (i.e., crevasses of closest-packed secondary particles) was also calculated by using $R$ and $S_{2}$. The theory predicts that smaller pore size can be attained with smaller $R$ and $S_{2}$. Phase volume ratio $R$ was found to be determined through use of a theoretical equation on porosity, using experimental porosity $\operatorname{Pr}\left(\mathrm{d}_{4}\right)$ determined from electron micrographs and approximate of degree of collapse of a membrane $k^{\prime}\left(=L_{0} / L_{\mathrm{d}} ; L_{0}\right.$, thickness of cast solution; $L_{\mathrm{d}}$, that of dried membrane). Collapse of a hypothetical gel membrane during coagulation process explains well the findings that theoretical $N(r)$ coincides fairly well with that by EM method only when apparent phase volume ratio $R_{\mathrm{A}}$ is employed instead of $R$.

KEY WORDS Particle Growth Concept / Phase Separation / Porous Polymeric Membrane / Pore Size Distribution / Hexagonal Lattice / Secondary Particle / Vacant Particle / Cellulose Cuprammonium Solution / Collapse /
\end{abstract}

In the previous papers, ${ }^{1,2}$ we proposed a theory of nucleation (steps a and $b$ in Figure 1), growth of nuclei to the primary particles (steps $b-d$ in Figure 1), and growth of the primary particles to the secondary particles (steps $\mathrm{d}-\mathrm{f}$ in Figure 1) in the process of formation of the porous polymeric membranes by the phase separation method (i.e., solvent- casting method) in the case when initial polymer volume fraction $v_{\mathrm{p}}^{0}$ is less than the polymer volume fraction at a critical solution point $v_{\mathrm{p}}^{\mathrm{c}}$. In subsequent steps, the secondary particles contact with each other to form gel membranes, which become dried membrane through desolvation and drying (steps $\mathrm{g}-\mathrm{j}$ in Figure 1). 


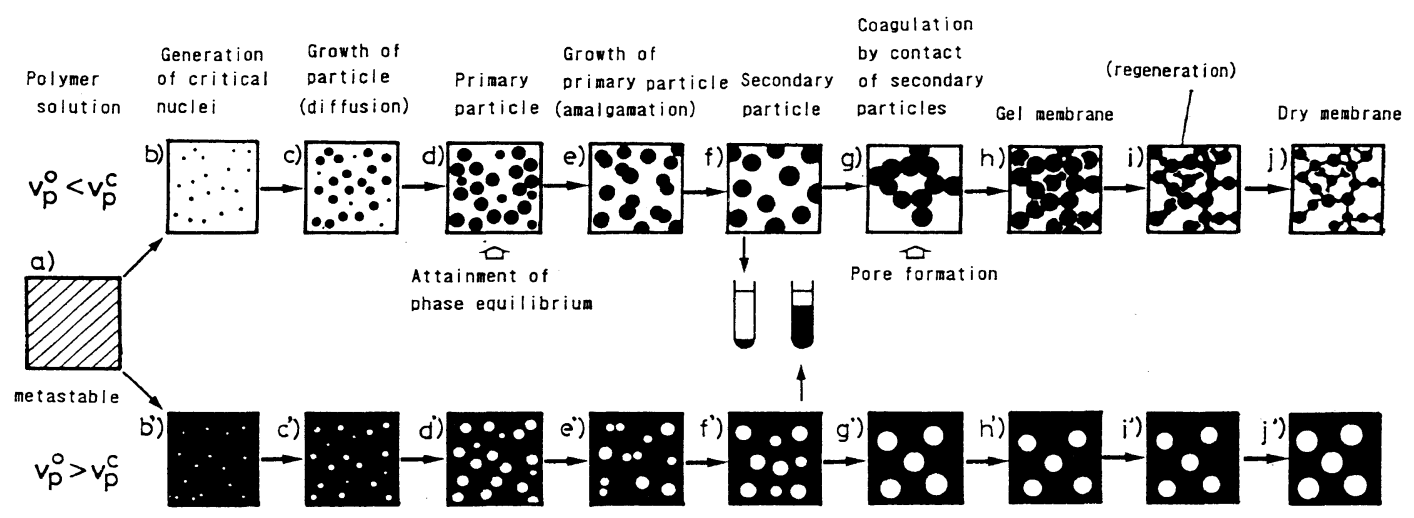

Figure 1. Elementary steps in porous polymeric membrane formation by the phase separation method: $v_{\mathrm{p}}^{0}$, polymer volume fraction of the solution when the phase separation occurs; $v_{\mathrm{p}}^{\mathrm{c}}$, polymer volume fraction of critical solution point; steps a and $f-j$ correspond to those of $a$ and $f-j$ in Figure 10 , respectively.

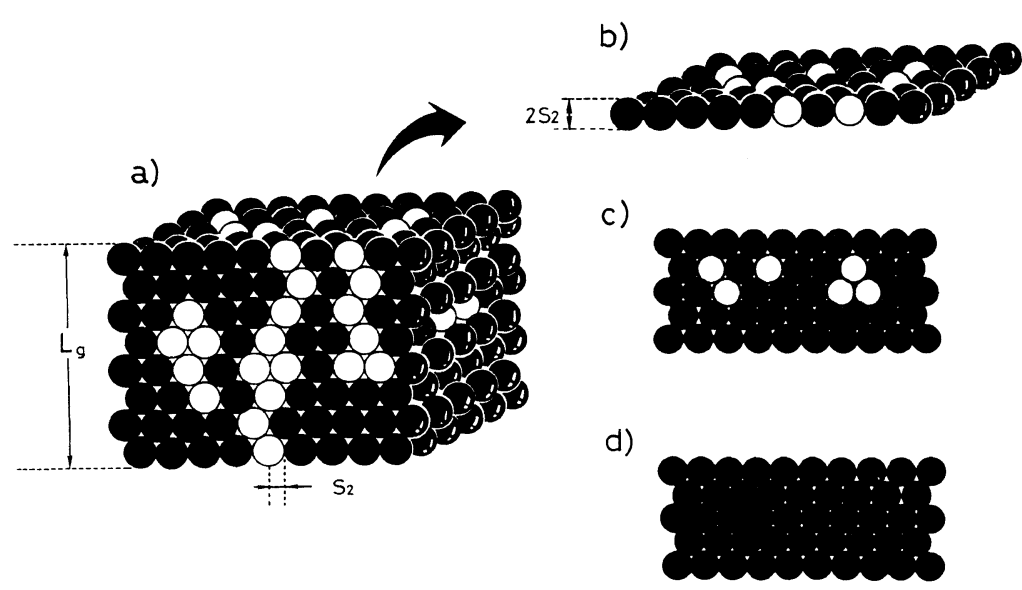

Figure 2. Schematic representation of a membrane structure and pores: a), A multi-layer model of a membrane; filled sphere, polymer particle; unfilled sphere, vacant particle; diameter of these spheres are $2 S_{2} ;$ b), A hypothetical plane; c) Vacant-particle pores on a hexagonal closest packing lattice; d) Inter-polymer-particle pores brought about by contacted polymer particles.

Based on electron microscopic observation of membranes prepared by the solvent-casting method, Kamide et al. proposed "particle growth concept" on membrane formation mechanism in the phase separation method (Figure 1) 3 "4 and "two-dimensional thin layer model" of membrane surface (Figure 2b) ${ }^{4}$ which consists of the secondary particles of polymer-rich phase (referred to as "polymer particles") with radii of $S_{2}$ and hypothetical particles of polymer-lean phase (referred to as "vacant particles"), whose radii are also $S_{2}$. In the thin layer model, regarding a portion consisting of contacting vacant particles as pores, whose boundary should be fully surrounded by polymer particles (Figure 2c; we define these pores as "vacant-particle pores"), Kamide and Manabe (KM) ${ }^{4}$ attempted to derive an tentative equation of pore radius distribution $N(r) \quad(r$, radius of pore) of membranes as a function of $S_{2}$ and two phase volume ratio at the instant when phase separation occurs $R\left(\equiv V_{(1)} / V_{(2)} ; V_{(1)}\right.$ and $V_{(2)}$ are volumes of polymer-lean and -rich phases, 
respectively), which is indirectly calculated from porosity $\mathrm{Pr}$ of a membrane evaluated by an electron micrographic (EM) method. ${ }^{5}$

Unfortunately, $N(r)$ of KM theory contains the following unnegligible drawbacks: a) In calculation of probability of appearance of the vacant-particle pore with $x$ vacant particles $P(x)$, a portion which does not contain any vacant particle (i.e., $x=0$ ) is mistakenly considered as a vacant-particle pore. Furthermore, $P(x)$ was normalized over the range of $x=0$ to $x=N_{\mathrm{T}} L$. Here, $N_{\mathrm{T}}$ is a total number of both particles (polymer- and vacantparticles) in the unit area of the plane (see, eq 1) and $L$ is volume fraction of polymer-lean phase (see, eq 2). Accordingly, the final equation of $N(r)$ can not ascertain the existence of $N_{\mathrm{P}}$ vacant-particle pores in unit area by $\mathrm{KM}$ theory. b) They thought that $R$ could be indirectly determined from $\operatorname{Pr}$ by EM method, however, $R$ thus calculated often deviates significantly from $R$ directly determined in actual phase separation experiments. c) Even if $x=0$, small crevasses are formed between closely-packed polymer particles and these crevasses should be regarded as pores, which we define as inter-polymer-particle pores, but these crevasses were not considered in KM theory. These inter-polymer-particle pores must be taken into consideration independently. d) Pore density $N_{\mathbf{P}}$ can not be determined explicitly for a given condition of $R$ and $S_{2}$.

Recently, Kamide et $a l .{ }^{6}$ disclosed for membranes by the phase separation method that the over-all supermolecular structure changed significantly depending on the distance from the top surface of a membrane and within a given thin layer with the constant distance from the surface, the particular supermolecular structure of the layer remained almost uniform, and that $N(r)$ for each portion of the ultra-thin layer was constant for a given distance. These experimental facts leaded them to the conclusion that porous polymeric membrane prepared by the phase separation method should be considered as a composite, in which many hypothetical ultra-thin layers are piled up, and they presented a "three-dimensional structure model" of a membrane, assuming that the over-all supermolecular structure is uniform (Figure 2a). ${ }^{7}$

In this article, we attempted (1) to derive a reliable equation of $N(r)$ for vacant-particle pores of a thin layer using $R$ and $S_{2}$ (eq 24) by improving the drawback a) of the previous KM theory, (2) to interpret the experimental disagreement between two kinds of $R$; the one is calculated indirectly from $P r$ evaluated by EM method and the other is directly determined in actual phase separation experiments [drawback b) in KM theory], by considering collapse (steps $\mathrm{g}-\mathrm{h}$ in Figure 1) of gel membranes, with the three-dimensional model of a membrane (Figure 2a), proposing a new concept of apparent phase volume ratio $R_{\mathrm{A}}$ (eq 39), (3) to derive equations for pore density of inter-polymer-particle pores and pore size distribution of them using $R$ and $S_{2}$ (eq 31 and 34 , respectively) [drawback c)], and (4) to give concrete physical meanings of determining $N_{\mathrm{P}}$ value from the boundary condition [drawback d)], demonstrating effects of $R$ and $S_{2}$ on $N(r)$.

\section{THEORETICAL BACKGROUND}

\section{Lattice Theory for Vacant-Particle Pore}

Pore Radius Distribution. After the growing particles approached their asymptotic size (i.e., the secondary particle; step $f$ in Figure 1), the particles contact with each other forming pores by settling the coagulated solution without any further agitation (step $g$ in Figure 1).

Assume that a membrane consists of multi-layers (see, Figure 2a) and that the pore characteristics of a hypothetical plane within the membrane, parallel to the membrane surface is kept the same. ${ }^{6}$ Consider a hypothetical plane with thickness $2 S_{2}$, parallel to the surface of the coagulated solution and assume that the solution consists of the polymer particles with radius of $S_{2}$ and "hypothetical particles" of 
polymer-lean phase, whose radius is also $S_{2}$ (see, Figure 2b). Let the number of the polymer particles per unit area of the plane be represented by $N_{\mathrm{T}} /(R+1)$ and that of the hypothetical polymer-lean particles (referred to as "vacant particles") by $N_{\mathrm{T}} R /(R+1)$. Here, $N_{\mathrm{T}}$ is a total number of both particles in the unit area of the plane and is roughly estimated as

$$
N_{\mathrm{T}}=\frac{1}{\left(\pi S_{2}^{2}\right)} .
$$

Obviously, a group of vacant particles contact directly with each other, building a pore. Hereafter, we call this pore a vacant-particle pore (Figure 2c). A total number of vacantparticle pores per unit surface area (i.e., pore density) is represented by $N_{\mathbf{p}}$.

Assume that polymer particles and hypothetical vacant particles are placed randomly on a two-dimensional hexagonally close-packed lattice of the hypothetical plane to evaluate number of distinguishable arrangements of the mixtures of the polymer particles and the vacant particles on the lattice (Figures $2 b$ and 2c). In this sense, the lattice coordination number is six. In the hypothetical planes of a gel membrane, a portion whose boundary is fully surrounded by polymer particles and which is concurrently occupied by the consecutively connected vacant particles yields a vacant-particle pore (Figure $2 \mathrm{c}$ ). Here, we neglect the crevasse of the contacted polymer particles (Figure 2d), which will be discussed as inter-polymer-particle pore later.

The pore size can be approximately represented by the number $x$ of vacant particles constituting a single vacant-particle pore. And a pore radius $r$ distribution $N(r)$ for vacantparticle pores can be evaluated by translating a distribution of the number $x$ of vacant particles constituting single pores on the hexagonal lattice sites. Consider the case when $N_{\mathrm{T}} L$ vacant particles are divided into $N_{\mathrm{P}}$ cells. Here, $L$ is volume fraction of polymer-lean phase given by the following equation,

$$
L=\frac{R}{R+1} .
$$

To ascertain the existence of $N_{\mathbf{P}}$ pores beforehand, one vacant particle is, in advance of counting, distributed to each cell. The number of ways, $W_{N_{\mathrm{P}}}\left(N_{\mathrm{T}} L-N_{\mathrm{P}}\right)$ of partitioning the remaining $\left(N_{\mathrm{T}} L-N_{\mathrm{P}}\right)$ vacant particles into $N_{\mathrm{P}}$ cells is given by

$$
W_{N_{\mathrm{P}}}\left(N_{\mathrm{T}} L-N_{\mathrm{P}}\right)=\frac{\left\{\left(N_{\mathrm{P}}-1\right)+\left(N_{\mathrm{T}} L-N_{\mathrm{P}}\right)\right\} !}{\left(N_{\mathrm{P}}-1\right) !\left(N_{\mathrm{T}} L-N_{\mathrm{P}}\right) !} .
$$

After ascertaining the existence of $N_{\mathrm{P}}$ vacantparticle pores by distributing one vacant particle to all $N_{\mathrm{P}}$ cells, a single pore, arbitrarily chosen, is fulfilled with $(x-1)$ vacant particles further to realize the pore with $x$ vacant particles. Next, the number of ways, $W_{N_{\mathrm{P}}-1}\left(N_{\mathrm{T}} L-N_{\mathrm{P}}-x+1\right)$, of partitioning the remaining $\left(N_{\mathrm{T}} L-N_{\mathrm{P}}-x+1\right)$ vacant particles into $\left(N_{\mathbf{P}}-1\right)$ pores (i.e., all the pores except for the pore filled with $x$ vacant particles and note that the single pore has already $x$ vacant particles) is given by

$$
\begin{aligned}
& W_{N_{\mathrm{P}}-1}\left(N_{\mathrm{T}} L-N_{\mathrm{P}}-x+1\right) \\
& =\frac{\left\{\left(N_{\mathrm{P}}-2\right)+\left(N_{\mathrm{T}} L-N_{\mathrm{P}}-x+1\right)\right\} !}{\left(N_{\mathrm{P}}-2\right) !\left(N_{\mathrm{T}} L-N_{\mathrm{P}}-x+1\right) !} .
\end{aligned}
$$

Accordingly, when $N_{\mathrm{P}}$ pores are formed by partitioning $N_{\mathrm{T}} L$ vacant particles, the desired probability $P(x)$ that $x$ vacant particles are partitioned in a given pore is

$$
\begin{aligned}
P(x) & =\frac{W_{N_{\mathrm{P}}-1}\left(N_{\mathrm{T}} L-N_{\mathrm{P}}-x+1\right)}{W_{N_{\mathrm{P}}}\left(N_{\mathrm{T}} L-N_{\mathrm{P}}\right)} \\
& =\frac{\left(N_{\mathrm{T}} L-x-1\right) !\left(N_{\mathrm{P}}-1\right) !\left(N_{\mathrm{T}} \mathrm{L}-N_{\mathrm{P}}\right) !}{\left(N_{\mathrm{P}}-2\right) !\left(N_{\mathrm{T}} \mathrm{L}-N_{\mathrm{P}}-x+1\right) !\left(N_{\mathrm{T}} L-1\right) !}
\end{aligned}
$$




$$
=\frac{\left(N_{\mathrm{T}} L-N_{\mathrm{P}}\right)\left(N_{\mathrm{T}} L-N_{\mathrm{P}}-1\right) \cdots\left(N_{\mathrm{T}} L-N_{\mathrm{P}}-x+2\right)\left(N_{\mathrm{P}}-1\right)}{\left(N_{\mathrm{T}} L-1\right)\left(N_{\mathrm{T}} L-2\right) \cdots\left(N_{\mathrm{T}} L-x\right)} .
$$

Assuming that $N_{\mathrm{P}} \gg 1$ and $N_{\mathrm{T}} L-N_{\mathrm{P}} \gg x$, eq 5 can be simplified into

$$
P(x) \cong \frac{\left(1-\frac{N_{\mathrm{P}}}{N_{\mathrm{T}} L}\right)^{x}}{\left(\frac{N_{\mathrm{T}} L}{N_{\mathrm{P}}}-1\right)}
$$

for $1 \leq x<N_{\mathrm{T}} L$ and $N_{\mathrm{P}}<N_{\mathrm{T}} L$.

On the other hand, for $N_{\mathrm{P}}=N_{\mathrm{T}} L, x$ becomes unity and

$$
P(x)=1 .
$$

It should be noted that $P(x)$ is normalized for the range of $x=1$ to $\infty$,

$$
\sum_{x=1}^{\infty} \frac{\left(1-\frac{N_{\mathrm{P}}}{N_{\mathrm{T}} L}\right)^{x}}{\left(\frac{N_{\mathrm{T}} L}{N_{\mathrm{P}}}-1\right)}=1 .
$$

Here, $N_{\mathrm{T}} L$ vacant particles are consumed to build $N_{\mathrm{P}}$ pores and then the following equation of the boundary condition of vacant particles holds,

$$
\sum_{x=1}^{N_{\mathrm{T}} L} N_{\mathrm{P}} x P(x)=N_{\mathrm{T}} L
$$

By rewriting eq 9 average $x$ can be defined as follows:

$$
\bar{x}=\frac{N_{\mathrm{T}} L}{N_{\mathrm{P}}} \quad \text { for } \quad N_{\mathrm{T}} L \gg 1 .
$$

The radius of pore containing $x$ vacant particles in wet gel membrane $r_{\text {Wet }}$ is defined by the relation that area of a circular pore with radius $r_{\text {Wet }}\left(=\pi r_{\text {Wet }}{ }^{2}\right)$ is equal to the summation of area of the maximum cross section of $x$ vacant particles $\left(=x \pi S_{2}{ }^{2}\right)$, that is

$$
r_{\mathrm{Wet}}=x^{1 / 2} S_{2} .
$$

When the radius of wet polymer particles $S_{2}$ decreases to $S_{2}{ }^{\prime}$ during drying (Figure 3 ), the following equation holds.

$$
\frac{4}{3} \pi{S_{2}}^{\prime 3} d_{\mathrm{P}}{ }^{\prime}=\left(\frac{4}{3} \pi S_{2}{ }^{3}\right) v_{\mathrm{P}(2)} d_{\mathrm{PL}},
$$

that is

$$
S_{2}{ }^{\prime}=S_{2}\left(\frac{v_{\mathrm{P}(2)} d_{\mathrm{PL}}}{d_{\mathrm{P}}{ }^{\prime}}\right)^{1 / 3}
$$

where $v_{\mathbf{p}(2)}$ is polymer volume fraction of the polymer rich-phase in equilibrium, and $d_{\mathrm{PL}}$ and $d_{\mathrm{p}}{ }^{\prime}$ are densities of the polymer itself and of the dried polymer particles, respectively. In other words, the volume of a polymer particle decreases to $\left(4 \pi S_{2}{ }^{3} / 3\right) v_{\mathrm{P}(2)}\left(d_{\mathrm{PL}} / d_{\mathrm{P}}{ }^{\prime}\right)$ after drying.

Accordingly, the pore radius of dry membrane $r$ is related to the pore radius $r_{\text {Wet }}$ corresponding to $S_{2}$ of the wet gel membrane through the relation (Figure 3):

$$
r=r_{\text {Wet }}+\left\{1-\left(\frac{v_{\mathrm{P}(2)} d_{\mathrm{PL}}}{d_{\mathrm{P}}{ }^{\prime}}\right)^{1 / 3}\right\} S_{2} .
$$

Combination of eq 11 with eq 14 gives

$$
r=\left\{x^{1 / 2}+1-\left(\frac{v_{\mathrm{P}(2)} d_{\mathrm{PL}}}{d_{\mathrm{P}}^{\prime}}\right)^{1 / 3}\right\} S_{2} .
$$

a)

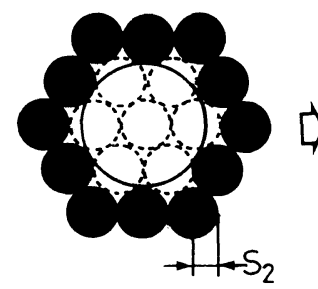

b)

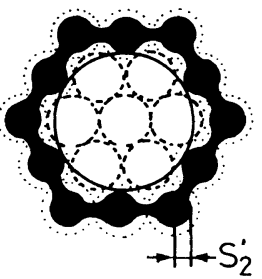

Figure 3. Change in a pore size during drying treatment under constant membrane width: a), A circular pore containing seven vacant particles (i.e., $x=7$ ) in a wet gel membrane; filled circles, polymer particles; broken line circles, vacant particles; both kinds of particles have the same radius of $S_{2}$; b), An enlarged pore in a dry membrane; $S_{2}{ }^{\prime}$, a radius of a dry polymer particle; $S_{2}{ }^{\prime}<S_{2}$ (see, eq 13 ). 
At $x=1, r$ given by eq 15 attains the minimum of radius of vacant-particle pore consisting of a single vacant particle, $r_{\text {min }}$ :

$$
r_{\min }=\left\{2-\left(\frac{v_{\mathrm{P}(2)} d_{\mathrm{PL}}}{d_{\mathrm{P}}{ }^{\prime}}\right)^{1 / 3}\right\} S_{2} .
$$

As the existing probability of the pore with the radius in the range from $r$ to $(r+\mathrm{d} r)$ is the same as that of the pore consisting of $x$ to $(x+\mathrm{d} x)$ vacant particles, the following relation holds:

$$
\begin{gathered}
\left(\begin{array}{l}
\text { Probability density of } \\
\text { the pore with radius } r
\end{array}\right) \times \mathrm{d} r \\
=\left(\begin{array}{l}
\text { Probability density of the pore } \\
\text { consisting of } x \text { vacant particles }
\end{array}\right) \times \mathrm{d} x \\
\qquad \frac{N_{\mathrm{v}}(r)}{N_{\mathrm{P}}} \mathrm{d} r=P(x) \mathrm{d} x
\end{gathered}
$$

where $N_{\mathrm{v}}(r)$ is the not-normalized pore radius distribution for vacant-particle pores which satisfies

$$
\int_{0}^{\infty} N_{\mathrm{v}}(r) \mathrm{d} r=N_{\mathrm{P}} .
$$

Equation 17 can be rewritten to yield

$$
N_{\mathrm{v}}(r)=N_{\mathrm{P}} P(x) \frac{\mathrm{d} x}{\mathrm{~d} r} .
$$

On the other hand, eq 15 can be rewritten as

$$
x=\left[\frac{r}{S_{2}}-\left\{1-\left(\frac{v_{\mathrm{P}(2)} d_{\mathrm{PL}}}{d_{\mathrm{P}}{ }^{\prime}}\right)^{1 / 3}\right\}\right]^{2}
$$

and differentiation of eq 20 by $r$ gives

$$
\frac{\mathrm{d} x}{\mathrm{~d} r}=\frac{2}{S_{2}}\left[\frac{r}{S_{2}}-\left\{1-\left(\frac{v_{\mathrm{P}(2)} d_{\mathrm{PL}}}{d_{\mathrm{P}}{ }^{\prime}}\right)^{1 / 3}\right\}\right]
$$

In deriving eq 21 , we assume that $P(x)$ can be approximated by the continuous function and there exists one-to-one correspondence between $x$ and $r$, in other words, all the pores in a plane have the same shape (that is, circular).

It should be noted that $x$ is a function of $r$, $S_{2}$ and $v_{\mathrm{p}(2)}$ at the constant $d_{\mathrm{PL}}$ and $d_{\mathrm{P}}{ }^{\prime}$ values and accordingly, $N_{\mathrm{v}}(r)$ is a function of $r, S_{2}$, $v_{\mathrm{p}(2)}, N_{\mathrm{P}}$, and $R$ in the forms:

$$
x=x\left(r, S_{2}, v_{\mathbf{p}(2)}\right)
$$

and

$$
\begin{gathered}
N_{\mathrm{v}}(r)=N_{\mathbf{P}} P\left(x\left(r, S_{2}, v_{\mathbf{P}(2)}\right), N_{\mathbf{P}}, L(\mathrm{R})\right) \\
\times \frac{\mathrm{d} x\left(r, S_{2}, v_{\mathbf{P}(2)}\right)}{\mathrm{d} r} \\
=N_{\mathrm{v}}\left(r, S_{2}, v_{\mathrm{P}(2)}, N_{\mathrm{P}}, R\right) .
\end{gathered}
$$

Combination of eq $6,10,19,20$, and 21 leads to

$$
\begin{aligned}
& N_{\mathrm{v}}(r)=\frac{2 N_{\mathrm{P}}}{S_{2}}\left(\frac{1}{\bar{x}-1}\right) \\
& \times\left(1-\frac{1}{\bar{x}}\right)^{\left[\frac{r}{S_{2}}-\left\{1-\left(\frac{v_{\mathrm{p}(2)} d_{\mathrm{PL}}}{d_{\mathrm{P}^{\prime}}}\right)^{1 / 3}\right\}\right]^{2}} \\
& \times\left[\frac{r}{S_{2}}-\left\{1-\left(\frac{v_{\mathrm{P}(2)} d_{\mathrm{PL}}}{d_{\mathrm{P}}^{\prime}}\right)^{1 / 3}\right\}\right] \\
& \text { for } r \geq r_{\text {min }}
\end{aligned}
$$

where

$$
\bar{x}=\frac{R}{\pi S_{2}^{2}(R+1) N_{\mathrm{P}}} .
$$

Equation 25 is derived from eq 1, 2, and 10 . From eq 24 it is clear that $N(r)$ for vacantparticle pores can be evaluated from $R, S_{2}$, and $N_{\mathrm{P}}$ data if $v_{\mathrm{p}(2)}, d_{\mathrm{PL}}$, and $d_{\mathrm{P}}{ }^{\prime}$ are given in advance.

Pore Density. $N_{\mathrm{T}} L$ vacant particles are thus partitioned on $N_{\mathrm{T}}$ sites of the hexagonal lattice in the manner so as to build up $N_{\mathrm{P}}$ vacantparticle pores. However, a single vacantparticle pore should be an assembly of vacant particles, which can take various forms under the condition that at least any vacant particle contacts directly with another vacant particle or with other vacant particles directly. Consequently, this assembly can give pores with various pore shapes, which make further calculation extremely difficult. Then, for the sake of simplicity, we assume that the assembly of vacant particles (forming a single vacantparticle pore) has a strong tendency to form a 
a)

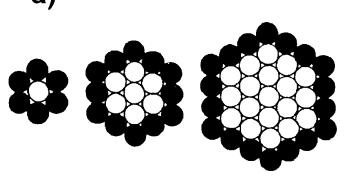

$f_{H}(1)=6 \quad f_{H}(7)=12 \quad f_{H}(19)=18$

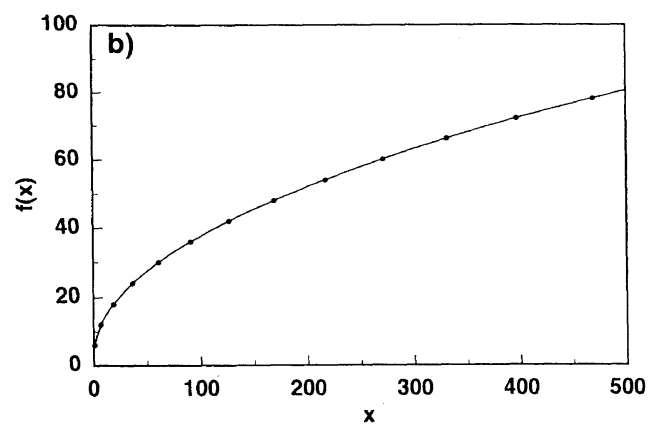

Figure 4. Approximation of a pore shape and number of polymer particles needed to surround an assembly of $x$ vacant particles: a), Schematic representation of regular hexagonal pores consisting of $x_{\mathrm{H}}$ vacant particles which are fully surrounded by $f_{\mathrm{H}}\left(x_{\mathrm{H}}\right)$ polymer particles; $x_{\mathrm{H}}=1$, $f_{\mathrm{H}}\left(x_{\mathrm{H}}\right)=6 ; x_{\mathrm{H}}=7, f_{\mathrm{H}}\left(x_{\mathrm{H}}\right)=12 ; x_{\mathrm{H}}=19, f_{\mathrm{H}}\left(x_{\mathrm{H}}\right)=18 ; x_{\mathrm{H}}=37$, $f_{\mathrm{H}}\left(x_{\mathrm{H}}\right)=24$; b) Relationship between $x$ and $f(x)$; points indicate $x_{\mathrm{H}}$ and $f_{\mathrm{H}}\left(x_{\mathrm{H}}\right)$ of regular hexagonal pores; full line, $f(x)=(12 x-3)^{1 / 2}+3$.

circle and that on hexagonal lattice sites any assembly of vacant particles is regarded as hexagonal (Figure 4a).

When regular hexagonal vacant-particle pores consisting of $x_{\mathrm{H}}$ vacant particles are considered (i.e., $x_{\mathrm{H}}$ can be $1,7,19,37, \cdots$, as is clear from Figure $4 \mathrm{a}$ ), the minimum number of polymer particles needed to surround fully these regular hexagonal pores $f_{\mathrm{H}}\left(x_{\mathrm{H}}\right)$ is given by $\left\{\left(12 x_{\mathrm{H}}-3\right)^{1 / 2}+3\right\}$. If an assembly of vacant particles tends to form a circle, the length of its surrounding should be as short as possible, and in this case we can approximate the minimum number of polymer particles needed to surround fully an assembly of $x$ vacant particles $f(x)$ by eq 26 ,

$$
f(x)=\sqrt{12 x-3}+3 \quad(x \geq 1) .
$$

In Figure $4 \mathrm{~b}$, full line is $f(x)$ and closed circles are $f_{\mathrm{H}}\left(x_{\mathrm{H}}\right)$. a)

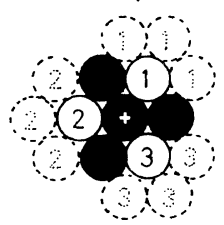

b)
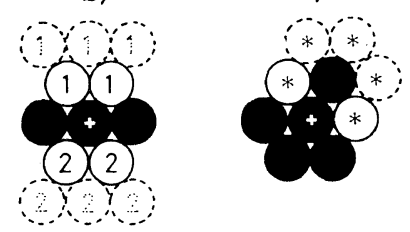

Figure 5. Some typical arrangements of polymer particles (filled circles) and vacant particles (unfilled circles) in the nearest neighbor of a given polymer particles (marked with + ): $m$, number of vacant particles existing around the given polymer particle in the center of the nearest neighbor sites; $n$, number of different pores which the given polymer particle can participate to form when the six nearest neighbor sites around the given polymer particle are considered; vacant particles constituting a pore are drawn with bearing the pore number (no. 1-3); dotted circle, vacant particles existing possibly outside of the six nearest neighbor sites under consideration; a), $m=3, n=3$; b), $m=4, n=2$; c) Two not-directly connected vacant particles (unfilled circle with $*$ ) connect indirectly by contacting with other vacant particles outside of the six nearest neighbor sites in order to form a common pore (dotted circle with $*$ ).

Figure 5a shows that a given polymer particle marked with $(+)$ mark on the lattice can contribute to the formation of at most three different pores when the six nearest neighbor sites of the given polymer particle are just considered. Here, these pores are numbered; 1 , 2 , and 3 . In Figure $5 b$, a given polymer particle with $(+)$ mark should be thought to participate in the formation of two different pores (no. 1 and 2).

When a single polymer particle is directly participated to the formation of $n$ pores $(1 \leq n \leq 3)$, (1) the reciprocal $n$ (i.e., $1 / n)$ is defined as contribution fraction of the polymer particle to the formation of one vacant-particle pore, and (2) the number $m$ of yacant particles existing around the particle (i.e., the number of the nearest neighbor vacant particles) lies between 1 and 5 (i.e., $1 \leq m \leq 5$ ) and (3) the probability $P_{n}(m)$ that a given polymer particle is surrounded in part by $m$ vacant particles, which belong to $n$ different pores is shown in Table I. Here, we assume that probability of appearance of a vacant particle and a polymer particle in every seat on the lattice is the same 
Table I. $P_{n}(m)$ values of hexagonal lattice

\begin{tabular}{ccccc}
\hline \multicolumn{5}{c}{$P_{n}(m)^{\mathrm{a}}$} \\
& \multicolumn{5}{c}{$n=2$} & $n=3$ \\
\cline { 2 - 5 } & $n=0$ & $n=1$ & - & - \\
\hline 0 & $(1-L)^{6}$ & - & - & - \\
1 & - & $6 L(1-L)^{5}$ & - & - \\
2 & - & $6 L^{2}(1-L)^{4}$ & $9 L^{2}(1-L)^{4}$ & - \\
3 & - & $6 L^{3}(1-L)^{3}$ & $12 L^{3}(1-L)^{3}$ & $2 L^{3}(1-L)^{3}$ \\
4 & - & $6 L^{4}(1-L)^{2}$ & $9 L^{4}(1-L)^{2}$ & - \\
5 & - & $6 L^{5}(1-L)$ & - & - \\
\hline$a$ &,- no theoretical possibility of a given combination \\
&
\end{tabular}

as $L$ and (1-L), respectively. In other words, particles are distributed on the hexagonal lattice randomly. When vacant particles are assumed to gather circularly, we can neglect the possibility that two not-directly connected vacant particles, which are the nearest neighbor of a given polymer particle, belong to a common pore (Figure $5 \mathrm{c}$ ), and $P_{1}(4) \approx 0$ and $P_{1}(5) \approx 0$ are expected.

Reciprocal $n, 1 / n$ can be averaged over all possible arrangements of the vacant particles and polymer particles around a distinguishable polymer particle:

$$
\left(\overline{\frac{1}{n}}\right)=\frac{\sum_{n=1}^{3}\left\{\sum_{m=1}^{5} \frac{1}{n} P_{n}(m)\right\}}{\sum_{n=1}^{3}\left\{\sum_{m=1}^{5} P_{n}(m)\right\}} .
$$

Then, it is clear that $\overline{(1 / n)}$ is determined by the volume fraction of polymer-lean phase $L$, accordingly by the two-phase volume ratio $R$.

In this manner, in order to form $N_{\mathrm{P}}$ vacant-particle pores, $N_{\mathrm{T}} L$ vacant particles are partitioned into $N_{\mathrm{P}}$ hexagonal assemblies. The number of the assemblies, each consisting of $x$ vacant particles, is $N_{\mathrm{P}} P(x)$ and the number of polymer particles consumed in order to surround fully an assembly with $x$ vacant particles, $f(x)$, is given by eq 26 .

The total number of the polymer particles directly surrounding $N_{\mathrm{P}}$ independent pores should be the total number of the polymer particles which contribute to form vacantparticle pores;

$\sum_{x=1}^{N_{\mathrm{T}} L}\left\{\left(\begin{array}{c}\text { Number of vacant- } \\ \text { particle pores } \\ \text { consisting of } x \\ \text { vacant particles }\end{array}\right)\right.$
$\times\left(\begin{array}{c}\text { Number of polymer particles } \\ \text { surrounding the vacant- } \\ \text { particle pore consisting } \\ \text { of } x \text { vacant particles }\end{array}\right)$

$\left.\times\left(\begin{array}{c}\text { Average contribution fraction of one } \\ \text { polymer particle to the formation } \\ \text { of one vacant-particle pore }\end{array}\right)\right\}$ $=\left(\begin{array}{c}\text { Total number of } \\ \text { polymer particles }\end{array}\right)$

$\times\left(\begin{array}{c}\text { Probability that a given } \\ \text { polymer particle contributes } \\ \text { to form vacant-particle pores }\end{array}\right)$,

that is

$$
\begin{aligned}
& \sum_{x=1}^{N_{\mathrm{T}} L} N_{\mathrm{P}} P(x) f(x)\left(\overline{\frac{1}{n}}\right) \\
& =N_{\mathrm{T}}(1-L)\left[1-\frac{P_{0}(0)}{\sum_{n=0}^{3}\left\{\sum_{m=0}^{5} P_{n}(m)\right\}}\right] \\
& =N_{\mathrm{T}}(1-L)\left[\frac{\sum_{n=1}^{3}\left\{\sum_{m=1}^{5} P_{n}(m)\right\}}{\sum_{n=0}^{3}\left\{\sum_{m=0}^{5} P_{n}(m)\right\}}\right],
\end{aligned}
$$

which is the boundary condition of polymer particles.

Equation 28 can be rewritten as follows:

$$
N_{\mathrm{P}}=\frac{N_{\mathrm{T}}(1-L)\left[\frac{\sum_{n=1}^{3}\left\{\sum_{m=1}^{5} P_{n}(m)\right\}}{\sum_{n=0}^{3}\left\{\sum_{m=0}^{5} P_{n}(m)\right\}}\right]}{\left(\overline{\frac{1}{n}}\right) \sum_{x=1}^{N_{\mathrm{T}} L} f(x) P(x)}
$$




$$
=\frac{N_{\mathbf{T}}(1-L)\left[\frac{\sum_{n=1}^{3}\left\{\sum_{m=1}^{5} P_{n}(m)\right\}}{\sum_{n=0}^{3}\left\{\sum_{m=0}^{5} P_{n}(m)\right\}}\right]}{\left(\frac{1}{n}\right) \overline{f(x)}}
$$

(for $N_{\mathrm{T}} L \gg 1$ )

$$
=\frac{\left(\begin{array}{c}
\text { Total number of polymer } \\
\text { particles which contribute to } \\
\text { form vacant-particle pores }
\end{array}\right)}{\left(\begin{array}{c}
\text { Average number of polymer } \\
\text { particles which contribute to } \\
\text { form one vacont-particle pore }
\end{array}\right)} .
$$

When we employ $P_{n}(m)$ given by Table I, in other words, polymer particles and vacant particles are placed randomly on the lattice, eq 28 always holds its validity. Here, we define $N_{\mathrm{P}}$ value, which satisfies eq 28 , as $N_{\mathrm{P}(\mathrm{v})} . N_{\mathrm{P}}$ decreases when vacant particle has a tendency to be partitioned in the nearest neighbor of another vacant particle. $N_{\mathrm{P}(\mathrm{v})}$ should be taken as $N_{\mathbf{P}}$ theoretically expected for a given combination of $R$ and $S_{2}$ under the random distribution of particles.

Accordingly, if $R$ and $S_{2}$ are given and values of $N_{\mathrm{T}}, L$ and $\overline{(1 / n)}$ are calculable, we can obtain
$N_{\mathrm{P}(\mathrm{v})}$ numerically. Route of calculation of $N_{\mathrm{P}(\mathrm{v})}$ for vacant-particle pores is illustrated in Figure 6. Note that $N_{\mathrm{P}(\mathrm{v})}<N_{\mathrm{T}} L$ (i.e., $\bar{x}>1$ ) should always hold. For $N_{\mathrm{P}(\mathrm{v})}=N_{\mathrm{T}} L$, eq 7 is used instead of eq 6 .

\section{Inter-Polymer-Particle Pore}

Even if the polymer particles occupy all the sites of the hexagonal close-packed lattice (i.e., $R=0$ ), there are numerous small crevasses between the polymer particles and such crevasses act as pores, as in the case of reverse osmosis membranes, and are hereafter referred to as inter-polymer-particle pores (Figure 2d) in order to distinguish them from the vacant-particle pores and the crevasse in wet gel membrane becomes large during drying when the dimension of the membrane is kept constant.

Consider a polymer particle with $m$ nearest neighbor vacant particles, belonging to $n$ different pores and having $n_{(\mathrm{i})}$ inter-polymerparticle pores. When $m=0$ (and accordingly, $n=0), n_{(\mathrm{i})}=6$ is obtained. In this manner, we can calculate $n_{(i)}$ value for a given combination of $m$ and $n$, as shown in Figure 7. Cases such as $m=0$ and $n=1$ are not theoretically realized and shown as blanks with a slash mark in Figure 7. In a case of $m=3$ and $n=3$, there is

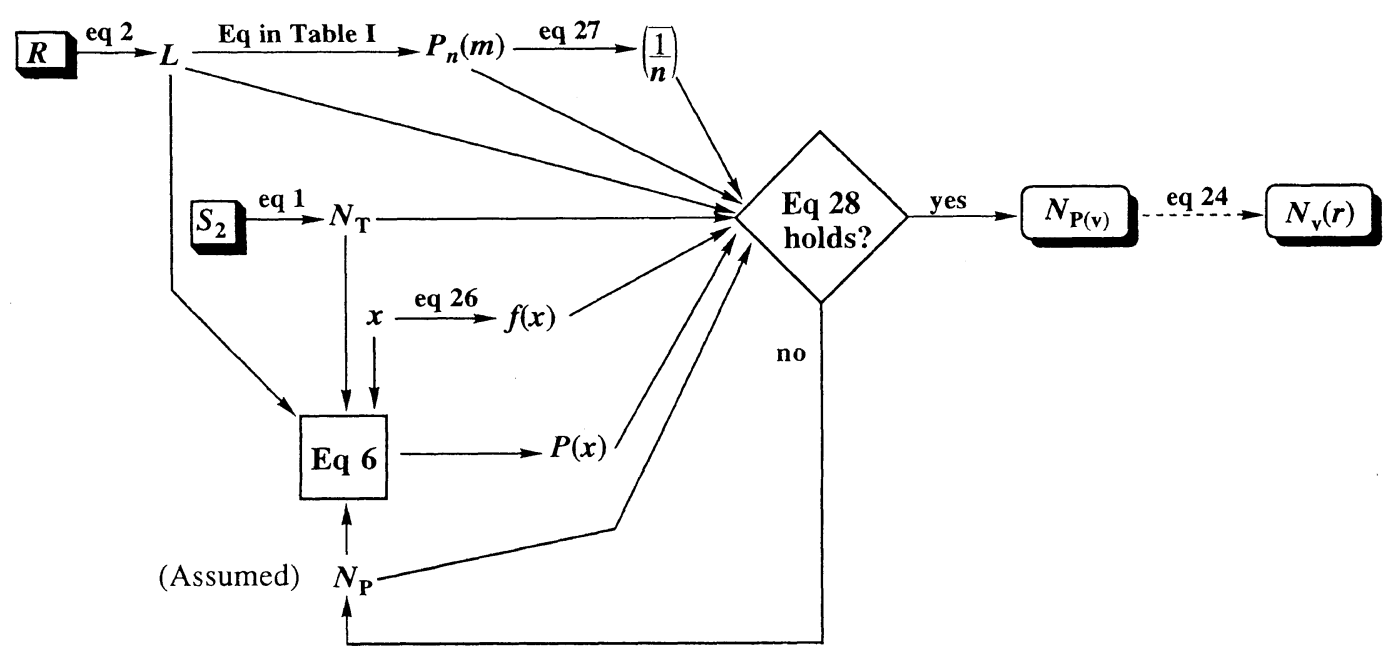

Figure 6. Route of calculation of $N_{\mathrm{P}(\mathrm{v})}$ for vacant-particle pores from $R$ and $S_{2}$. 


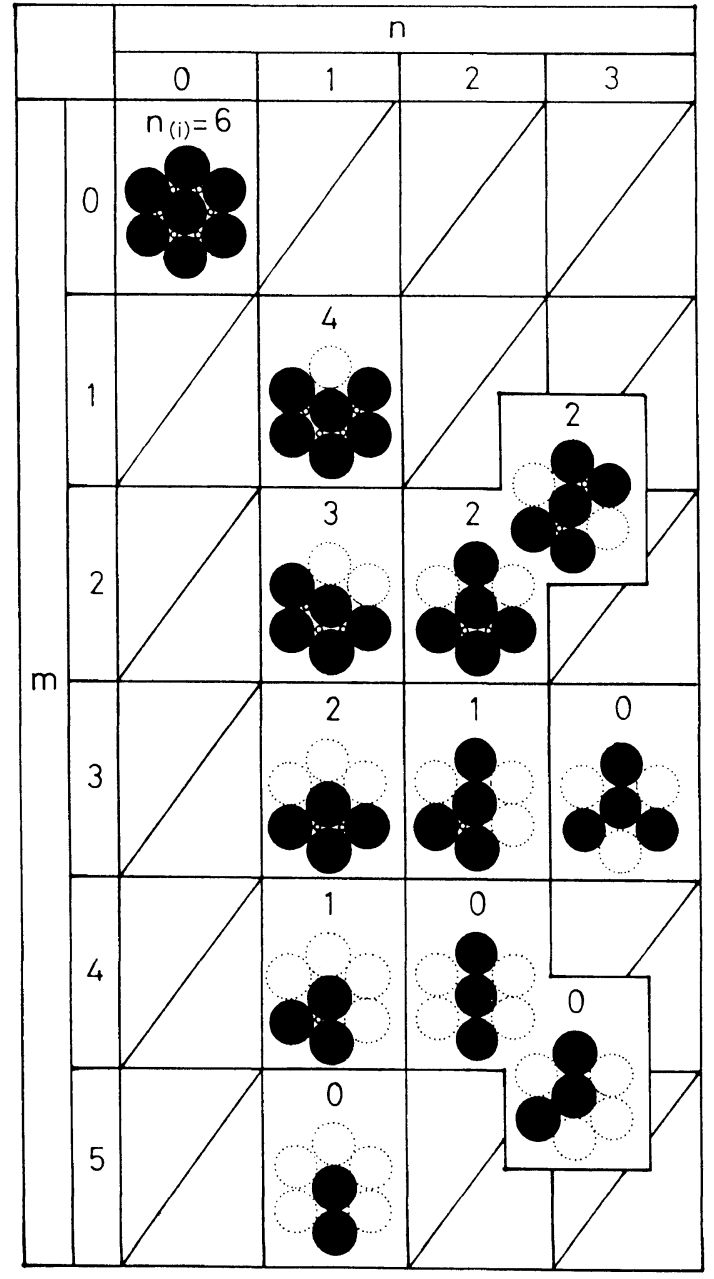

Figure 7. Theoretically possible arrangements of interpolymer-particle pores existing around a given polymer particle: Six nearest neighbor sites around a given polymer particle are just considered; $n_{(i)}$, number of the interpolymer-particle pores; $m$, number of vacant particles existing around the given polymer particle in the center; $n$, number of different pores which the given polymer particle can participate to form; filled circle, polymer particle; dotted unfilled circle, vacant particle; small unfilled circle, inter-polymer-particle pore.

no probability of finding inter-polymer particle pores (i.e., $\left.n_{(\mathbf{i})}=0\right)$.

Then, the average number of inter-polymerparticle pores directly contacted with a given single polymer particle, $\bar{n}_{(\mathrm{i})}$ is given by

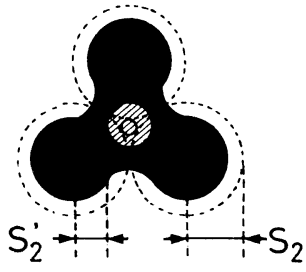

Figure 8. Change in pore size of an inter-polymer particle pore after drying: Broken line circle, wet polymer particle; full line circle in hatched area, wet inter-polymer-particle pore; $S_{2}$, radius of a wet polymer particle; $S_{2}{ }^{\prime}$, radius of a dry polymer particle; hatched area, inter-polymer particle pore after drying; blacked area, dry polymer particle.

$$
\overline{n_{(\mathrm{i})}}=\frac{\sum_{n=0}^{3}\left\{\sum_{m=0}^{5} n_{(\mathrm{i})} P_{n}(m)\right\}}{\sum_{n=0}^{3}\left\{\sum_{m=0}^{5} P_{n}(m)\right\}} .
$$

As one inter-polymer-particle pore contacts three polymer particles, a number of interpolymer-particle pores in unit area of a membrane $N_{\mathbf{P}(\mathbf{i})}$ is

$$
N_{\mathbf{P}(\mathbf{i})}=\frac{N_{\mathrm{T}}(1-L) \overline{n_{(\mathrm{i})}}}{3} .
$$

An inter-polymer-particle pore is formed by mutual contact of three polymer particles and the radius of the inter-polymer-particle pore, $r_{(i) w e t}$ of a wet gel membrane, which is noticed by the radius of an inscribed circle, is related to $S_{2}$ through the relation,

$$
r_{\text {(i)Wet }}=\left(\frac{2}{\sqrt{3}}-1\right) S_{2} .
$$

After drying $S_{2}$ changes to $S_{2}{ }^{\prime}$ (eq 13), keeping its center at the same position, as shown in Figure 8 and the radius of the inter-polymer-particle pore of dry membrane $r_{(i)}$ is readily obtained by adding the difference between $S_{2}$ and $S_{2}{ }^{\prime}$ in eq 13 to $r_{(\mathrm{i}) \mathrm{Wet}}$ in eq 32 :

$$
\begin{aligned}
r_{(\mathrm{i})} & =r_{(\mathrm{i}) \mathrm{Wet}_{\mathrm{et}}}+\left(S_{2}-S_{2}{ }^{\prime}\right) \\
& =\left(\frac{2}{\sqrt{3}}-1\right) S_{2}+\left\{1-\left(\frac{v_{\mathrm{p}(2)} d_{\mathrm{PL}}}{d_{\mathrm{P}}{ }^{\prime}}\right)^{1 / 3}\right\} S_{2}
\end{aligned}
$$




$$
=\left\{\frac{2}{\sqrt{3}}-\left(\frac{v_{\mathrm{p}(2)} d_{\mathrm{PL}}}{d_{\mathrm{P}}^{\prime}}\right)^{1 / 3}\right\} S_{2} .
$$

The pore size distribution $N(r)$ for interpolymer-particle pores, denoted by $N_{\mathrm{i}}(r)$ can be given as:

$$
N_{\mathrm{i}}(r)=N_{\mathrm{P}(\mathrm{i})} \delta\left(r-r_{(\mathrm{i})}\right)
$$

where $\delta(r)$ is the $\delta$-function which satisfies

$$
\int_{-\infty}^{\infty} \delta(r) \mathrm{d} r=1 .
$$

Schema of calculating $N_{\mathbf{P}(\mathrm{i})}$ and $N_{\mathrm{i}}(r)$ is shown in Figure 9. Note again that eq 24 and 34 are derived assuming that the super-particle structure (morphology) of coagulated polymer particles does not change through collapse during the phase separation (step $f$ of Figure 1), the coagulation (step g) and drying (step j). At a latter step, radius of the polymer particle changes only by a factor of $\left(v_{\mathrm{p}(2)} d_{\mathrm{PL}} / d_{\mathrm{P}}{ }^{\prime}\right)$.

\section{Porosity of Membranes}

Gel Membranes. Suppose that a polymer solution is cast on a plate to give a thin solution film with a thickness of $L_{0}$ (Figure 10a): In wet method, the cast solution is dipped in a coagulating solution consisting of nonsolvent(s). In dry method, the cast solution is settled in an atmosphere of nonsolvent(s). Phase separation occurs at the surface of the cast solution and it proceeds from the surface to the inner part of solution (Figures $10 \mathrm{~g}$ and

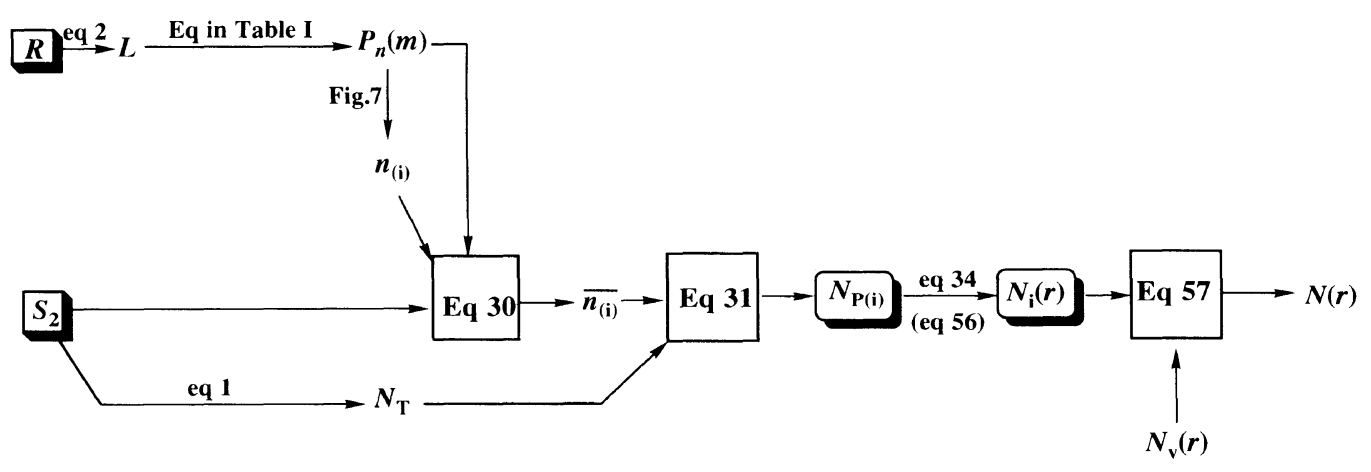

Figure 9. Route of calculation of $N_{\mathrm{P}(\mathrm{i})}$ and $N_{\mathrm{i}}(r)$ for inter-polymer-particle pores from $R$ and $S_{2}$.

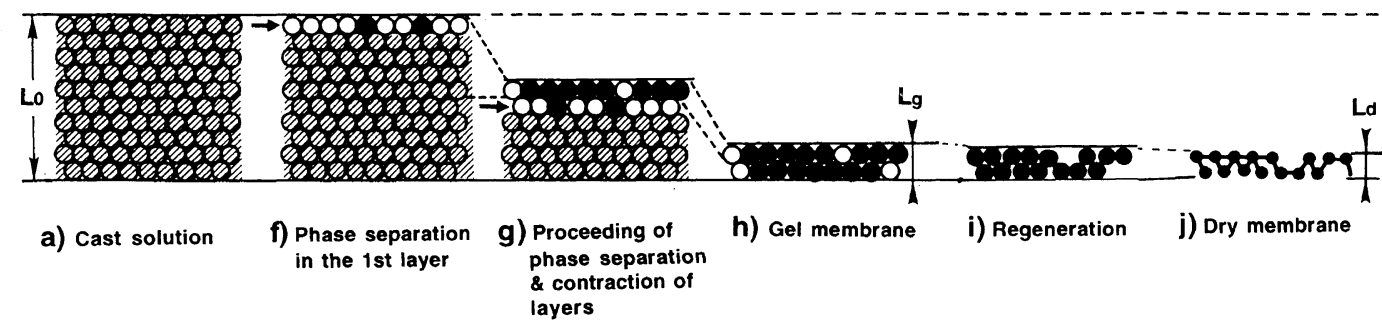

Figure 10. Schematic representation of changes of membrane thickness during membrane formation process: a), Casting of polymer solution; f), Starting of the phase separation; g), Proceeding of phase separation and contraction of thin layers; h), Gel membrane (end of the over-all phase separation); i), Regeneration; j), Dry membrane; unfilled circle, vacant particle; filled circle, polymer particle; hatched area, homogeneous polymer solution not yet phase-separated; unfilled circle in the hatched area, position of particles to be created by phase separation; $L_{0}$, thickness of cast solution; $L_{\mathrm{g}}$, thickness of gel membrane; $L_{\mathrm{d}}$, thickness of dry membrane; arrows indicate a layer where the phase separation has just occurred and the layer-contraction has not occurred yet; steps a and $\mathrm{f}-\mathrm{j}$ correspond to those of a and $\mathrm{f}-\mathrm{j}$ in Figure 1 , respectively. 
10h). We define the volume fraction of a polymer-lean phase in a hypothetical layer at the moment of phase separation as $\operatorname{Pr}(\mathrm{PS})$, which is given by the relation

$$
\operatorname{Pr}(\mathrm{PS})=\frac{R}{R+1} .
$$

During the progress of phase separation, the thickness of the cast solution decreases and a coagulated gel membrane with thickness $L_{\mathrm{g}}$ is formed (Figure 10h). The volume fraction of vacant particles in the gel membrane $\operatorname{Pr}(\mathrm{GEL})$ is governed by the degree of collapse of thin layers.

In a case where two hypothetical layers having the same $\operatorname{Pr}(\mathrm{PS})$ collapse into a "single layer", it is required that a vacant particle in the upper layer is just superposed with another vacant particle in the lower layer in order to find a vacant particle in the "single layer". The probability of occurrence of the above phenomenon (i.e., the porosity) is $\{\operatorname{Pr}(\mathrm{PS})\}^{2}$. Accordingly, $\operatorname{Pr}(\mathrm{GEL})$ is equal to the porosity of a "single layer" formed by the collapse of $k$ hypothetical layers is given by

$$
\operatorname{Pr}(\mathrm{GEL})=\{\operatorname{Pr}(\mathrm{PS})\}^{k}=\left(\frac{R}{R+1}\right)^{k} .
$$

Here, the following relation holds approximately:

$$
k \cong \frac{L_{0}}{L_{\mathrm{g}}} .
$$

The porosity of gel membranes consisting of collapsed hypothetical layers, $\operatorname{Pr}($ GEL $)$ is equivalent with apparent volume fraction of polymer-lean phase $L_{\mathrm{A}}$.

Next, we define apparent phase volume ratio $R_{\mathrm{A}}$ by the relation

$$
R_{\mathrm{A}}=\frac{\left(\frac{R}{R+1}\right)^{k}}{1-\left(\frac{R}{R+1}\right)^{k}}
$$

For the gel membranes formed after collapse of hypothetical layers, $R$ in eq 25 should be substituted with $R_{\mathrm{A}}$ in calculation of $N(r)$.

$L_{\mathrm{A}}(=\operatorname{Pr}(\mathrm{GEL}))$ is defined by

$$
L_{\mathrm{A}}=\frac{R_{\mathrm{A}}}{R_{\mathrm{A}}+1}
$$

and it should be substituted with $L$ in calculation of eq $3-6$, eq $8-10$, eq $27-31$, and equations in Table I.

Dry Membranes. After gel membranes with thickness $L_{\mathrm{g}}$ are formed, the membrane is treated with acid for generation of cellulose (if necessary) and washed and dried.

Considering an increase in volume of both vacant-particle pores and inter-polymers-particle pores due to de-solvation of polymer particles in drying step, the porosity of dry membrane $\operatorname{Pr}(\mathrm{d})$ (as denoted by $\operatorname{Pr}\left(\mathrm{d}_{1}\right)$ ) is given by eq 41 ,

$$
\begin{aligned}
\operatorname{Pr}\left(\mathrm{d}_{1}\right) & =\left\{1-\left(\frac{S_{2}^{\prime}}{S_{2}}\right)^{3}\right\}\left(1-L_{\mathrm{A}}\right)+L_{\mathrm{A}} \\
& =\left(1-\frac{v_{\mathrm{p}(2)} d_{\mathrm{PL}}}{d_{\mathrm{P}}^{\prime}}\right)\left(1-L_{\mathrm{A}}\right)+L_{\mathrm{A}} .
\end{aligned}
$$

$S_{2}{ }^{\prime}$ is the radius of dry polymer particle (see, eq 13). In deriving eq 41 , it is assumed that pore density $N_{\mathrm{P}}$ does not change during drying step, and $\operatorname{Pr}\left(\mathrm{d}_{1}\right)$ represents the summation of porosity of vacant-particle pores and that of inter-polymer-particle pores.

\section{EXPERIMENTAL}

\section{Preparation of Cellulose Membranes}

Cellulose cuprammonium solution with the cellulose concentration (weight fraction) $w_{\text {Cell }}=$ 0.04 to 0.09 was prepared by diluting with ammonium-water solution (the weight fraction of ammonia $w_{\mathrm{NH}_{3}}=0.28$ ) an original cellulose cuprammonium solution, whose compositions were $w_{\text {Cell }}=0.10$, the weight fraction of copper $w_{\mathrm{Cu}}=0.0395, w_{\mathrm{NH}_{3}}=0.0703$, and the weight fraction of water $w_{\mathrm{H}_{2} \mathrm{O}}=0.7902$.

Cellulose cuprammonium solutions with $w_{\text {Cell }}$ 
of 0.04 to 0.10 were cast on flat glass plates, respectively. The cast solutions, having $500 \mu \mathrm{m}$ thickness $\left(=L_{0}\right)$, cast on the glass plates, were immersed in a coagulating solution containing acetone, ammonia and water (the weight fraction of acetone $w_{\text {Acetone }}: w_{\mathrm{NH}_{3}}: w_{\mathrm{H}_{2} \mathrm{O}}=$ $0.30: 0.0056: 0.6944)$ at $298.15 \mathrm{~K}$. After coagulation, the gel membranes were peeled off from the glass plates and treated with sulfuric acid-water solution (the weight fraction of sulfuric acid $=0.02$ ) at $293.15 \mathrm{~K}$, and then washed with water. The wet membranes were immersed in acetone and then dried at $298.15 \mathrm{~K}$ under fixed length without dimensional change. Thickness of dry membrane $L_{\mathrm{d}}$ was measured by using an upright dial gauge (manufactured by Ozaki Seisakusho Co., Japan).

Membranes thus prepared were embedded in blocked acrylic resin (a mixture of $n$-butyl acrylate and methyl methacrylate) and sliced using Ultrotome ${ }^{\circledR}$ type 8800 (manufactured by LKB., Sweden) in parallel to the membrane surface to give thin sections of $1 \mu \mathrm{m}$ thickness. The acrylic resin for embedding was removed by dissolving with chloroform. The sections obtained from their top surfaces were employed in scanning electron microscopic observation.

\section{Measurements}

Porosities of Membranes. The porosity of dry membrane was directly evaluated from apparent density $d_{\mathrm{A}}$ of the membrane and density of polymer constructing the membrane $d_{\mathrm{PL}}$ through use of eq $42 \mathrm{a}$. The porosity, determined by this method (apparent density method) was denoted as $\operatorname{Pr}\left(\mathrm{d}_{3}\right)$,

$$
\operatorname{Pr}\left(\mathrm{d}_{3}\right)=1-\frac{d_{\mathrm{A}}}{d_{\mathrm{PL}}}
$$

where $d_{\mathrm{A}}=w_{\mathrm{m}} / v_{\mathrm{m}}\left(w_{\mathrm{m}}, v_{\mathrm{m}}\right.$ are weight and volume of absolutely dry membrane, respectively). All pores such as through pores, semiopen pores, and independent pores ${ }^{3}$ existing in the membrane, and also cracks in polymer particles contribute to $\operatorname{Pr}\left(\mathrm{d}_{3}\right)$.
An effect of the cracks in polymer particles on $\operatorname{Pr}\left(\mathrm{d}_{3}\right)$ can be omitted if $d_{\mathbf{p}}{ }^{\prime}$ was used in eq $42 \mathrm{a}$ instead of $d_{\mathrm{PL}}$. We can estimate a real porosity of dry membrane $\operatorname{Pr}\left(\mathrm{d}_{3}\right)^{\prime}$ by the relation:

$$
\operatorname{Pr}\left(\mathrm{d}_{3}\right)^{\prime}=1-\frac{d_{\mathrm{A}}}{d_{\mathrm{P}}{ }^{\prime}} .
$$

Another kind of porosity of dry membrane $\operatorname{Pr}\left(\mathrm{d}_{4}\right)$ was determined from electron micrographs by eq $43,{ }^{8}$

$$
\operatorname{Pr}\left(\mathrm{d}_{4}\right)(\equiv \operatorname{Pr}(\mathrm{EM}))=\frac{\sum_{i} L_{\mathrm{C}, i}}{\sum_{i} L_{i}}
$$

where $L_{i}$ is the length of the $i$-th test lines drawn on a photograph of membrane surface and $L_{\mathrm{C}, i}$ is the cut-off length, by pores, of the $i$-th test line. $\operatorname{Pr}\left(\mathrm{d}_{4}\right)$ neglects the contribution of pores smaller than the resolution power of the scanning electron microscope employed and is suitable for the determination of the porosity of thin membrane or membrane whose whole pore characteristics can be well represented by those at the surface.

Density of dried polymer particles. Assuming that $\operatorname{Pr}\left(\mathrm{d}_{3}\right)^{\prime}$ is equal to $\operatorname{Pr}\left(\mathrm{d}_{4}\right)$ and combining of eq $42 \mathrm{a}, 42 \mathrm{~b}$, and 43 , the density of dried polymer particles $d_{\mathbf{p}}{ }^{\prime}$ is given by eq 44 ,

$$
d_{\mathrm{P}}{ }^{\prime}=\frac{\left\{1-\operatorname{Pr}\left(\mathrm{d}_{3}\right)\right\} d_{\mathrm{PL}}}{\left\{1-\operatorname{Pr}\left(\mathrm{d}_{4}\right)\right\}} .
$$

Electron micrographic method for determination of $S_{2}{ }^{\prime}$ and $N(r)$. Electron micrographs (EM) on the surface of membranes were taken using a field emission scanning electron microscope (FE-SEM S-800, manufactured by Hitachi, Ltd., Tokyo, Japan) and $S_{2}{ }^{\prime}$ was determined directly from the EM by averaging radii of polymer particles. The pore radius distribution $N(r)$ was evaluated from the EM by a stereological method. ${ }^{5}$

Phase Equilibria. Cellulose cuprammonium solutions with $w_{\text {Cell }}=0.05$ and 0.08 were 
prepared by adding ammonia-water solution $\left(w_{\mathrm{NH}_{3}}=0.28\right)$ to an original cellulose cuprammonium solution $\left(w_{\mathrm{Cell}}=0.10, w_{\mathrm{Cu}}=0.0395\right.$, $w_{\mathrm{NH}_{3}}=0.0703, w_{\mathrm{H}_{2} \mathrm{O}}=0.7902$ ). A given amount of the solution was poured into a closed glass vessel, to which a predetermined amount of acetone-water solution $\left(w_{\text {Acetone }}=0.30\right)$ was added, agitated sufficiently, stocked for a whole day at $298.15 \mathrm{~K}$, then the two phase volume ratio $R$ was measured.

The largest $R$ value, $R_{\max }$ was obtained when the experimentally permissible minimum amount of acetone-water solution, which brings about two-phase separation, was added to the cuprammonium solution, and we regarded that $R_{\max }$ corresponded to the casting condition of an actual membrane.

\section{RESULTS AND DISCUSSION}

Theoretical Predictions of the Correlation between the Casting Conditions and the Pore Characteristics of Membranes

Figure 11 shows the effect of the pore density $N_{\mathrm{P}}$ on pore size distribution $N(r)$, as estimated by eq 24, in two cases: $R=0.25$ and $S_{2}=250 \mathrm{~nm}$ (Figure 11a), and $R=1.0$ and $S_{2}=250 \mathrm{~nm}$ (Figure 11b). Other conditions are kept constant; $v_{\mathrm{p}(2)}=0.3, d_{\mathrm{PL}}=1.5 \times 10^{3} \mathrm{~kg} \mathrm{~m}^{-3}$, and $d_{\mathrm{p}}{ }^{\prime}=0.9 \times 10^{3} \mathrm{~kg} \mathrm{~m}^{-3}$. With an increase in $N_{\mathrm{P}}, N_{\mathrm{v}}(r)$ becomes sharper and its peak shifts to smaller $r$ region. Pore radius $r$ which gives the peak of $N_{\mathrm{v}}(r), r_{\text {peak }}$, and $N_{\mathrm{v}}\left(r_{\text {peak }}\right)$ are given by the following equations, respectively:

$$
r_{\text {peak }}=\left[\left\{1-\left(\frac{v_{\mathrm{p}(2)} d_{\mathrm{PL}}}{d_{\mathrm{P}}{ }^{\prime}}\right)^{1 / 3}\right\}+\frac{1}{\sqrt{2 \ln \frac{\bar{x}}{\bar{x}-1}}}\right] S_{2}
$$

and

$$
N_{\mathrm{v}}\left(r_{\text {peak }}\right)=\frac{2 N_{\mathrm{P}}}{S_{2}} \times \frac{\left(1-\frac{1}{\bar{x}}\right)^{\left(2 \ln \frac{\bar{x}}{\bar{x}-1}\right)^{-1}}}{(\bar{x}-1) \sqrt{2 \ln \frac{\bar{x}}{\bar{x}-1}}} .
$$
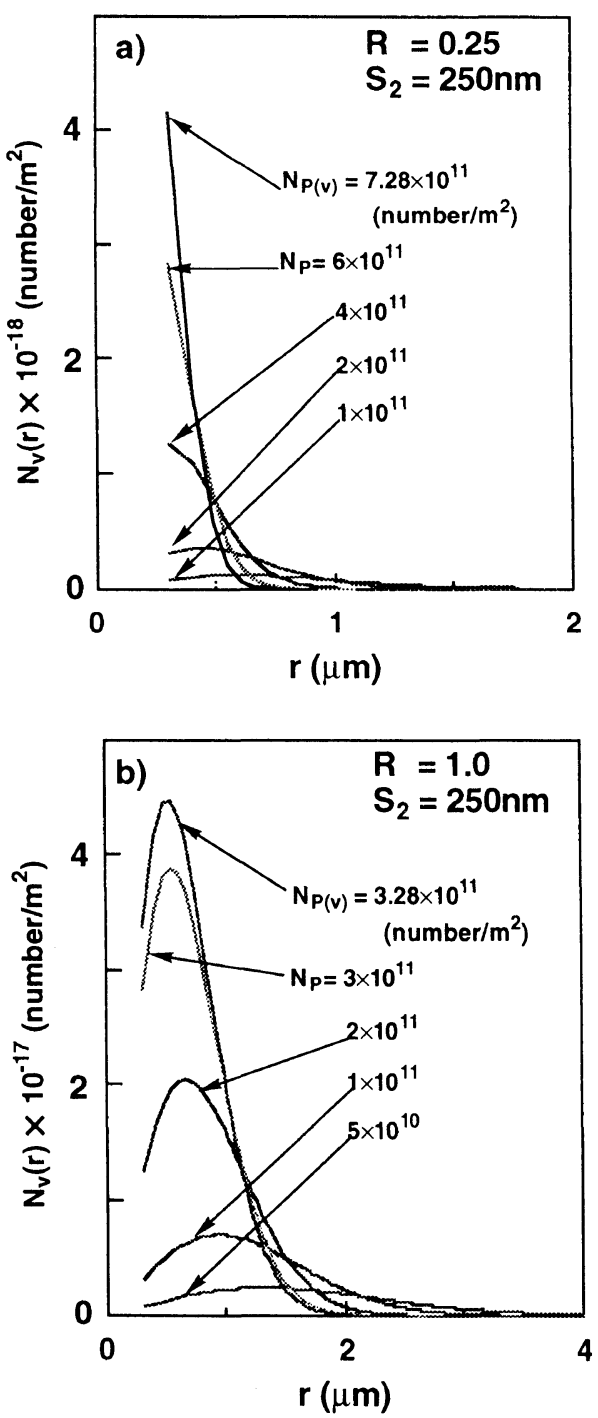

Figure 11. Effect of the pore density $N_{\mathrm{P}}$ on the pore size distribution $N_{\mathrm{v}}(r)$ (eq 24): Radius of a polymer particle $S_{2}, 250 \mathrm{~nm} ; N_{\mathrm{P}(\mathrm{v})}$, calculated along a route in Figure 6; $\left.v_{\mathrm{p}(2)}, 0.3 ; d_{\mathrm{PL}}, 1.5 \times 10^{3} \mathrm{~kg} \mathrm{~m}^{-3} ; d_{\mathrm{P}}{ }^{\prime}, 0.9 \times 10^{3} \mathrm{~kg} \mathrm{~m}^{-3} ; \mathrm{a}\right)$, Phase volume ratio $R, 0.25 ; \mathrm{b}), R, 1.0$.

The criteria that $N(r)$ has a peak at $r>r_{\min }$ is $r_{\text {peak }}>r_{\min }$. This expression can be rewritten using eq 45 for $r_{\text {peak }}$ and eq 16 for $r_{\text {min }}$ in the form,

$$
\bar{x}>\frac{1}{1-e^{-1 / 2}}(\approx 2.54) .
$$

Equation 47 can be again rewritten as a 

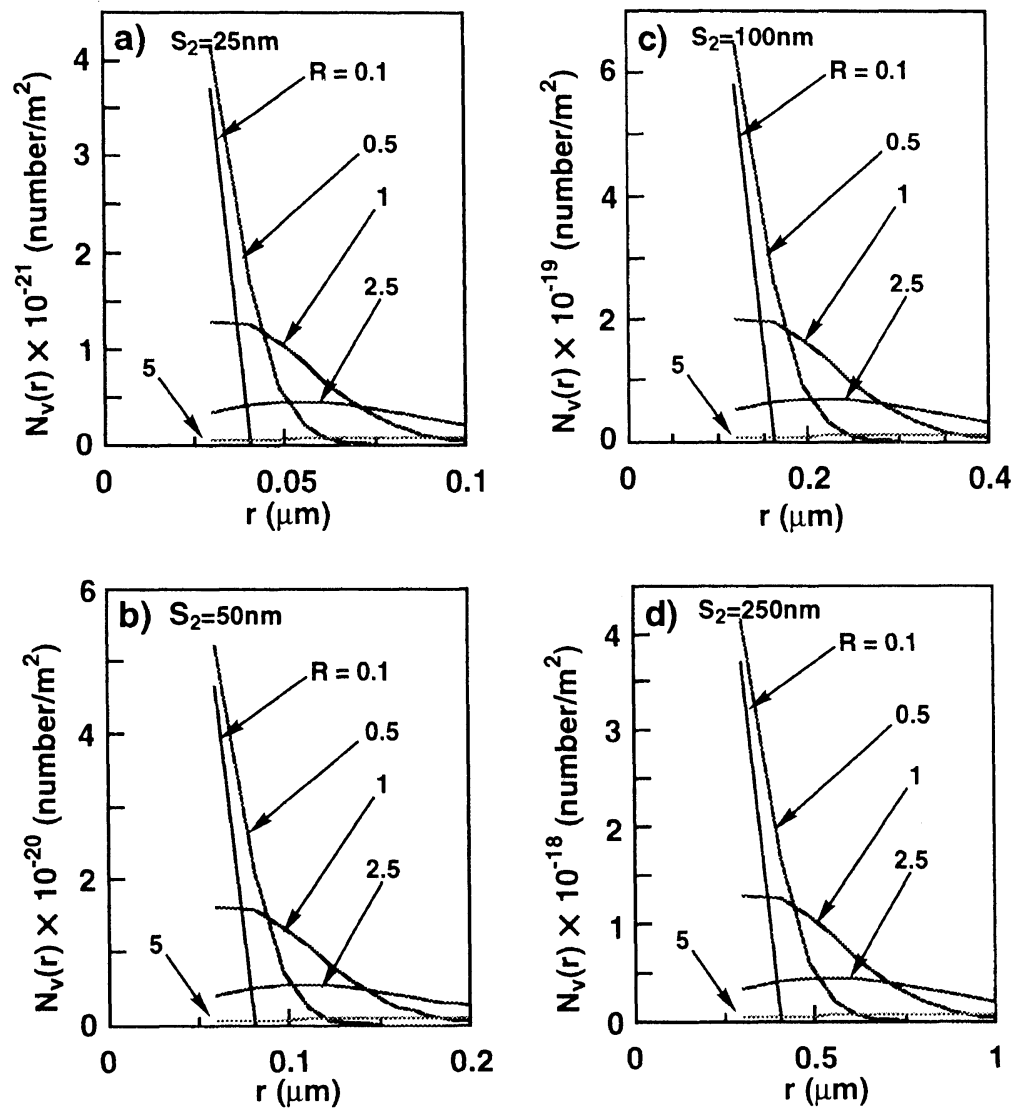

Figure 12. Effect of the two-phase volume ratio $R$ on the pore size distribution $N_{\mathrm{v}}(r)$ (eq 24): Values of $S_{2}, R$, and $N_{\mathrm{P}(\mathrm{v})}$ used in calculations and those of $\bar{x}, R_{\text {peak }}^{\prime}$, and $r_{\text {peak }}$ obtained are listed in Table II; $v_{\mathrm{p}(2)}, 0.3 ; d_{\mathrm{PL}}, 1.5 \times 10^{3} \mathrm{~kg} \mathrm{~m}^{-3} ; d_{\mathrm{P}}{ }^{\prime}, 0.9 \times 10^{3} \mathrm{~kg} \mathrm{~m}^{-3}$.

function of $S_{2}$ and $R$ in the form,

$$
N_{\mathrm{P}}<\frac{R\left(1-e^{-1 / 2}\right)}{\pi S_{2}{ }^{2}(R+1)}\left(\equiv N_{\mathrm{P}, \text { peak }}^{\prime}\right) .
$$

The peak disappears at $N_{\mathrm{P}} \geq 4 \times 10^{11}$ (number $\left.\mathrm{m}^{-2}\right)$ in Figure 11a. As $N_{\mathrm{P}(\mathrm{v})}\left(=3.28 \times 10^{11}\right.$ (number $\left.\mathrm{m}^{-2}\right)$ ) is smaller than $N_{\mathrm{P}, \text { peak }}^{\prime}(\approx 1 \times$ $10^{12}$ (number $\left.\mathrm{m}^{-2}\right)$ ) in Figure $11 \mathrm{~b}, N_{\mathrm{v}}(r)$ always has a peak.

Equation 47 can also be rewritten as a function of $S_{2}$ and $N_{\mathrm{P}}$ in the form,

$$
R>\frac{\pi S_{2}^{2} N_{\mathrm{P}}}{1-e^{-1 / 2}-\pi S_{2}{ }^{2} N_{\mathrm{P}}}\left(\equiv R_{\text {peak }}^{\prime}\right) .
$$

As far as eq $47 \mathrm{~b}$ holds its validity, $N_{\mathrm{v}}(r)$ has a peak.
Figure 12 shows the effect of the two-phase volume ratio $R$ on the pore size distribution $N_{\mathrm{v}}(r)$ when $S_{2}=25,50,100$, and $250 \mathrm{~nm}$ and $N_{\mathrm{P}}$ is taken as $N_{\mathbf{P}(\mathrm{v})}$ (i.e., random distribution of particles is attained). Other conditions are kept constant; $\quad v_{\mathrm{p}(2)}=0.3, \quad d_{\mathrm{PL}}=1.5 \times 10^{3} \mathrm{~kg}$ $\mathrm{m}^{-3}$, and $d_{\mathrm{p}}{ }^{\prime}=0.9 \times 10^{3} \mathrm{~kg} \mathrm{~m}^{-3}$. With an increase in $R$, the breadth of pore size distribution curve increases significantly with a shift of its peak to the larger $r$ side.

When polymer particles are placed randomly on the lattice (i.e., $N_{\mathbf{P}}=N_{\mathbf{P}(\mathrm{v})}$ ), the effect of the radius of the polymer particles $S_{2}$ on the pore size distribution $N_{\mathrm{v}}(r)$ can not be clarified by simply taking both $R$ and $N_{\mathrm{P}}$ constant, because $N_{\mathrm{P}(\mathrm{v})}$ changes in proportion to $1 /\left(S_{2}\right)^{2}$ even at 
constant $R$. Combining eq 1,2 , and 29, we obtain eq 48 . The equation indicates that $S_{2}{ }^{2} N_{\mathrm{P}(\mathrm{v})}$ is constant at constant $R$ (i.e., constant $L$ ). Average $x, \bar{x}$ (eq 10) also becomes constant

Table II. $\quad N_{\mathrm{P}(\mathrm{v})}, \bar{x}, R_{\text {peak }}^{\prime}$, and $r_{\text {peak }}$ for various $S_{2}$ and $R$

\begin{tabular}{|c|c|c|c|c|c|}
\hline$S_{2}$ & \multirow{2}{*}{$R$} & \multirow{2}{*}{$\begin{array}{c}N_{\mathrm{P}(\mathrm{v})} \\
\text { (number/ } \\
\mathrm{m}^{2} \text { ) }\end{array}$} & \multirow{2}{*}{$\begin{array}{c}\bar{x} \\
\text { (number/ } \\
\text { pore) }\end{array}$} & \multirow{2}{*}{$R_{\text {peak }}^{\prime}$} & \multirow{2}{*}{$\frac{r_{\text {peak }}{ }^{\mathbf{a}}}{\mathrm{nm}}$} \\
\hline $\mathrm{nm}$ & & & & & \\
\hline \multirow{6}{*}{10} & 0.1 & $2.05 \times 10^{14}$ & 1.41 & 0.196 & - \\
\hline & 0.25 & $2.95 \times 10^{14}$ & 2.16 & 0.308 & - \\
\hline & 0.5 & $2.78 \times 10^{14}$ & 3.82 & 0.285 & 14.9 \\
\hline & 1 & $1.73 \times 10^{14}$ & 9.21 & 0.160 & 22.9 \\
\hline & 2.5 & $4.64 \times 10^{13}$ & 49.0 & 0.038 & 51.3 \\
\hline & 5 & $1.29 \times 10^{13}$ & 206 & 0.010 & 103.5 \\
\hline \multirow{6}{*}{25} & 0.1 & $3.29 \times 10^{13}$ & 1.41 & 0.196 & - \\
\hline & 0.25 & $4.72 \times 10^{13}$ & 2.16 & 0.308 & - \\
\hline & 0.5 & $4.45 \times 10^{13}$ & 3.82 & 0.285 & 37.2 \\
\hline & 1 & $2.77 \times 10^{13}$ & 9.21 & 0.160 & 57.3 \\
\hline & 2.5 & $7.43 \times 10^{12}$ & 49.0 & 0.038 & 128.3 \\
\hline & 5 & $2.06 \times 10^{12}$ & 206 & 0.010 & 258.8 \\
\hline \multirow{6}{*}{50} & 0.1 & $8.22 \times 10^{12}$ & 1.41 & 0.196 & - \\
\hline & 0.25 & $1.18 \times 10^{13}$ & 2.16 & 0.308 & - \\
\hline & 0.5 & $1.11 \times 10^{13}$ & 3.82 & 0.285 & 74.5 \\
\hline & 1 & $6.29 \times 10^{12}$ & 9.21 & 0.160 & 114.6 \\
\hline & 2.5 & $1.86 \times 10^{12}$ & 49.0 & 0.038 & 256.6 \\
\hline & 5 & $5.14 \times 10^{11}$ & 206 & 0.010 & 517.6 \\
\hline \multirow{6}{*}{100} & 0.1 & $2.05 \times 10^{12}$ & 1.41 & 0.196 & - \\
\hline & 0.25 & $2.95 \times 10^{12}$ & 2.16 & 0.308 & - \\
\hline & 0.5 & $2,78 \times 10^{12}$ & 3.82 & 0.285 & 148.9 \\
\hline & 1 & $1.73 \times 10^{12}$ & 9.21 & 0.160 & 229.2 \\
\hline & 2.5 & $4.64 \times 10^{11}$ & 49.0 & 0.038 & 513.2 \\
\hline & 5 & $1.29 \times 10^{11}$ & 206 & 0.010 & 1035.1 \\
\hline \multirow{6}{*}{250} & 0.1 & $3.29 \times 10^{11}$ & 1.41 & 0.196 & - \\
\hline & 0.25 & $4.72 \times 10^{11}$ & 2.16 & 0.308 & - \\
\hline & 0.5 & $4.45 \times 10^{11}$ & 3.82 & 0.285 & 372.3 \\
\hline & 1 & $2.77 \times 10^{11}$ & 9.21 & 0.160 & 572.9 \\
\hline & 2.5 & $7.43 \times 10^{10}$ & 49.0 & 0.038 & 1282.9 \\
\hline & 5 & $2.06 \times 10^{10}$ & 206 & 0.010 & 2587.8 \\
\hline \multirow{6}{*}{500} & 0.1 & $8.22 \times 10^{10}$ & 1.41 & 0.196 & - \\
\hline & 0.25 & $1.18 \times 10^{11}$ & 2.16 & 0.308 & - \\
\hline & 0.5 & $1.11 \times 10^{11}$ & 3.82 & 0.285 & 744.6 \\
\hline & 1 & $6.92 \times 10^{10}$ & 9.21 & 0.160 & 1145.9 \\
\hline & 2.5 & $1.86 \times 10^{10}$ & 49.0 & 0.038 & 2565.8 \\
\hline & 5 & $5.14 \times 10^{9}$ & 206 & 0.010 & 5175.7 \\
\hline
\end{tabular}

for given $R . N_{\mathrm{P}(\mathrm{v})}$, which was numerically determined by using eq 28 , and $\bar{x}, R_{\text {peak }}^{\prime}$ and $r_{\text {peak }}$ for various $S_{2}$ are listed in Table II.

$$
S_{2}{ }^{2} N_{\mathrm{P}(\mathrm{v})}
$$

$$
=\frac{\sum_{n=1}^{3}\left\{\sum_{m=1}^{5} P_{n}(m)\right\}}{\pi(R+1)\left(\frac{1}{n}\right) \overline{f(x)}\left[\sum_{n=0}^{3}\left\{\sum_{m=0}^{5} P_{n}(m)\right\}\right]}
$$$$
=\text { constant } \text {. }
$$

From Figure 12, we can evaluate the effect of $S_{2}$ on $N_{\mathrm{v}}(r)$ under the condition of constant $R ; N_{\mathrm{v}}(r)$ becomes narrower and its peak becomes higher to a large extent with decrease in $S_{2}$.

When $N_{\mathrm{P}}$ in eq 24 is taken as $N_{\mathrm{P}(\mathrm{v})}, N_{\mathrm{v}}(r)$ for given $R$ can be represented by a master curve in the form,

$$
\begin{aligned}
& N^{*}\left(r^{*}\right)=\left(\frac{1}{\bar{x}-1}\right) \\
& \times\left(1-\frac{1}{\bar{x}}\right)^{\left[r^{*-}-\left\{1-\left(\frac{v_{\mathbf{p}(2)} d_{\mathbf{P L}}}{d_{\mathbf{P}^{\prime}}}\right)^{1 / 3}\right\}\right]^{2}} \\
& \times\left[r^{*}-\left\{1-\left(\frac{v_{\mathrm{P}(2)} d_{\mathrm{PL}}}{d_{\mathrm{P}}{ }^{\prime}}\right)^{1 / 3}\right\}\right] \\
& \text { for } r^{*} \geq 2-\left(\frac{v_{\mathrm{P}(2)} d_{\mathrm{PL}}}{d_{\mathrm{P}}{ }^{\prime}}\right)^{1 / 3}
\end{aligned}
$$

where $r^{*}=r / S_{2}$ and $N^{*}\left(r^{*}\right)=N_{\mathrm{v}}(r) S_{2} / 2 N_{\mathbf{P}(\mathrm{v})}$.

Figure 13 shows the plots of $N^{*}\left(r^{*}\right)$ versus $r^{*}$ for given $R$. The plot is a "master curve." With an increase in $R$, the curve becomes broader and the peak height decreases and the peak location shifts to the lager $r / S_{2}$ side. In Table II, $R_{\text {peak }}^{\prime}$ (eq 47b) and $r_{\text {peak }}$ (eq 45) are also listed. When $R>R_{\text {peak }}^{\prime}, N_{\mathrm{v}}(r)$ has a peak for $r>r_{\min } . N_{\mathrm{v}}(r)$ s for $R$ above 0.5 in Figure 13 have peaks at $r=r_{\text {peak }}$.

Both our theory and the computer experiments on the thermodynamics of phase separation indicate that the larger phase volume ratio $R$ will be realized when a polymer with lower weight-average degree of polym- 


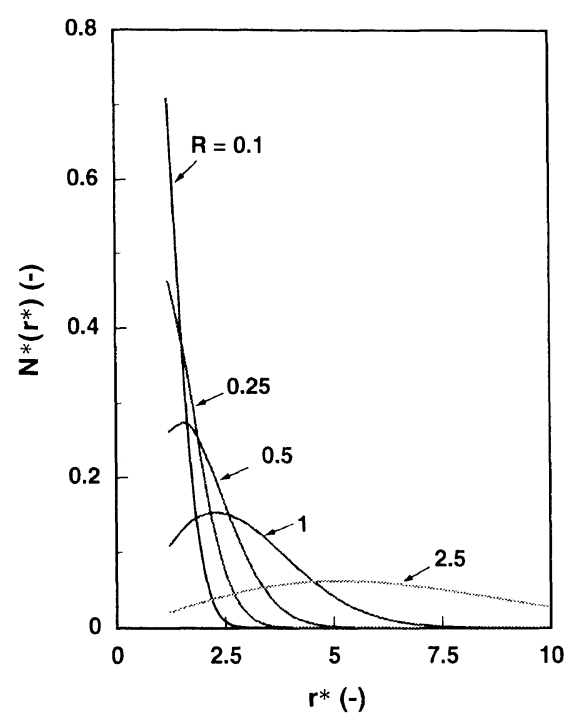

Figure 13. Effect of the two-phase volume ratio $R$ on the relation between $N^{*}\left(r^{*}\right)$ and $r^{*}$ : Value of $R$ is shown in the figure; $v_{\mathrm{p}(2)}, 0.3 ; d_{\mathrm{PL}}, 1.5 \times 10^{3} \mathrm{~kg} \mathrm{~m}^{-3} ; d_{\mathrm{P}}{ }^{\prime}, 0.9 \times 10^{3}$ $\mathrm{kg} \mathrm{m}^{-3}$.

erization $X_{w}$ and broader molecular distribution $X_{w} / X_{n}\left(X_{n}\right.$, the number-average degree of polymerization) is dissolved in a single solvent having larger $p_{1}$ (1st order concentrationdependent parameter of thermodynamic interaction parameter $\chi$ between solvent and polymer $)^{9-15}$ or in a binary solvent mixture with smaller $\chi_{12}$, larger $\chi_{13}$, smaller $\chi_{23}\left(\chi_{12}{ }^{0}\right.$, $\chi_{13}{ }^{0}, \chi_{23}{ }^{0}$; thermodynamics interaction parameter between solvent and nonsolvent, solvent and polymer, and nonsolvent and polymer, respectively) ${ }^{16-18}$ to give a dilute solution, which is phase-separated under the condition of a larger relative amount of polymer precipitated, $\rho_{\mathrm{p}}$.

\section{Porosity and Phase Volume Ratio}

If contribution of inter-polymer-particle pores can be neglected, $\operatorname{Pr}\left(\mathrm{d}_{1}\right)$ (eq 41) should be compared with the porosity of dry membrane $\operatorname{Pr}(\mathrm{d})$ (in this case $\operatorname{Pr}\left(\mathrm{d}_{2}\right)$ ) estimated through use of eq $50,{ }^{4}$

$$
\operatorname{Pr}\left(\mathrm{d}_{2}\right)=\pi N_{\mathrm{P}} \bar{r}^{2}
$$

where average pore radius $\bar{r}$ is defined using eq
10 and 15 by

$$
\bar{r}=\left\{\bar{x}^{1 / 2}+1-\left(\frac{v_{\mathrm{P}(2)} d_{\mathrm{PL}}}{d_{\mathrm{P}}{ }^{\prime}}\right)^{1 / 3}\right\} S_{2} .
$$

When volumetric increase due to interpolymer-particle pores during drying step are considered, $\operatorname{Pr}\left(\mathrm{d}_{2}\right)^{\prime}$ should be used as the porosity of dry membrane:

$$
\operatorname{Pr}\left(\mathrm{d}_{2}\right)^{\prime}=\pi\left\{N_{\mathrm{P}(\mathrm{v})} \bar{r}^{2}+N_{\mathbf{P}(\mathrm{i})} r_{(\mathrm{i})}{ }^{2}\right\}
$$

Table III lists the various kinds of the porosity defined above. Combining eq 40 and 41 , we obtain

$$
v_{\mathrm{P}(2)}=\frac{\left\{1-\operatorname{Pr}\left(\mathrm{d}_{1}\right)\right\}\left(R_{\mathrm{A}}+1\right) d_{\mathrm{P}}{ }^{\prime}}{d_{\mathrm{PL}}} .
$$

Giving $R_{\mathrm{A}}$ an appropriate value which satisfies the relation of $\operatorname{Pr}\left(\mathrm{d}_{1}\right)=\operatorname{Pr}\left(\mathrm{d}_{2}\right)^{\prime}$ under the assumption of $\operatorname{Pr}\left(\mathrm{d}_{1}\right)=\operatorname{Pr}\left(\mathrm{d}_{4}\right)$, we can determine $v_{\mathrm{p}(2)}$ and $R_{\mathrm{A}}$ by eq 53 .

\section{Collapse of Gel Membrane and its Porosity}

Cellulose cuprammonium solution cast on a glass plate (step a in Figure 10) contracts to give a gel membrane with a thickness of $c a .1 / 5$ of the cast solution $\left(L_{\mathrm{g}} \approx L_{0} / 5\right)$ and the thickness of dry membrane $L_{\mathrm{d}}$ becomes $c a$. $1 / 10$ of $L_{0}\left(L_{\mathrm{d}} \approx L_{0} / 10\right)$. Equation 39 reduces to eq 54 when $k$ is assumed to be $k^{\prime}$ given by eq 55 ,

$$
R=\frac{\left(\frac{R_{\mathrm{A}}}{R_{\mathrm{A}}+1}\right)^{1 / k^{\prime}}}{1-\left(\frac{R_{\mathrm{A}}}{R_{\mathrm{A}}+1}\right)^{1 / k^{\prime}}},
$$

where

$$
k^{\prime}=\frac{L_{0}}{L_{\mathrm{d}}} .
$$

$k^{\prime}$ values for regenerated cellulose membranes prepared under conditions of $w_{\text {Cell }}=$ 0.04 to 0.10 are listed in the third column of Table IV. Therefore, several hypothetical thin planes in the cast solution with a thickness of $L_{0}$ yield a new single hypothetical gel plane in the wet membrane (step $i$ in Figure 10), and 
H. Inima, S. Matsuda, and K. Kamide

Table III. Various kinds of porosity

\begin{tabular}{|c|c|c|c|c|}
\hline Type & Notation & Definition & $\mathrm{Eq}$ & Ref \\
\hline $\begin{array}{l}\text { Volume fraction of polymer- } \\
\text { lean phase in a hypothetical } \\
\text { layer at the moment of phase } \\
\text { separation }\end{array}$ & $\operatorname{Pr}(\mathrm{PS})(\equiv L)$ & $\frac{R}{R+1}$ & eq 36 & - \\
\hline $\begin{array}{l}\text { Porosity of gel membrane } \\
\text { after collapse of } k \text { layers }\end{array}$ & $\operatorname{Pr}(\mathrm{GEL})\left(\equiv L_{\mathrm{A}}\right)$ & $\left(\frac{R}{R+1}\right)^{k}$ & eq 37 & - \\
\hline Porosity of dry membrane & $\operatorname{Pr}\left(\mathrm{d}_{1}\right)$ & $\left\{1-\left(\frac{S_{2}^{\prime}}{S_{2}}\right)^{3}\right\}\left(1-L_{\mathrm{A}}\right)+L_{\mathrm{A}}$ & eq 41 & - \\
\hline Porosity of dry membrane & $\operatorname{Pr}\left(\mathrm{d}_{2}\right)$ & $\pi N_{\mathrm{P}} \bar{r}^{2}$ & eq 50 & 4 \\
\hline $\begin{array}{l}\text { Porosity of dry membrane } \\
\text { Porosity of dry membrane }\end{array}$ & $\begin{array}{l}\operatorname{Pr}\left(\mathrm{d}_{2}\right)^{\prime} \\
\operatorname{Pr}\left(\mathrm{d}_{3}\right)\end{array}$ & $\pi\left\{N_{\mathbf{P}(\mathbf{v})} \bar{r}^{2}+N_{\mathbf{P}(\mathbf{i})} r(\mathbf{i})^{2}\right\}$ & eq 52 & - \\
\hline $\begin{array}{l}\text { evaluated from apparent } \\
\text { density }\end{array}$ & $1\left(\mathrm{u}_{3}\right)$ & $1-\frac{d_{\mathbf{A}}}{d_{\mathrm{PL}}}$ & eq $42 a$ & - \\
\hline Porosity of dry membrane & $\operatorname{Pr}\left(\mathrm{d}_{3}\right)^{\prime}$ & $1-\frac{d_{\mathrm{A}}}{d_{\mathbf{P}}{ }^{\prime}}$ & eq $42 b$ & - \\
\hline $\begin{array}{l}\text { Porosity of dry membrane } \\
\text { determined by studying EM }\end{array}$ & $\operatorname{Pr}\left(\mathrm{d}_{4}\right)(\equiv \operatorname{Pr}(\mathrm{EM}))$ & $\frac{\sum_{i} L_{C, i}}{\sum_{i} L_{i}}$ & eq 43 & 8 \\
\hline
\end{tabular}

Table IV. Characteristics of actual membranes and condition of theoretical calculations of pore radius distribution for these membranes

\begin{tabular}{|c|c|c|c|c|c|c|c|c|}
\hline \multirow{3}{*}{$w_{\text {Cell }}{ }^{a}$} & \multicolumn{4}{|c|}{ Characteristics of actural membranes } & \multicolumn{4}{|c|}{ Condition of theoretical calculation ${ }^{\mathrm{b}}$} \\
\hline & $S_{2}{ }^{\mathrm{c}}$ & & & & $d_{\mathrm{P}}^{\prime}{ }^{\prime g}$ & & $S_{2}{ }^{\mathrm{i}}$ & \\
\hline & $\mathrm{nm}$ & $\kappa$ & $\left(\mathrm{a}_{3}\right)$ & & $10^{-3} \mathrm{~kg} \mathrm{~m}^{-3}$ & & $\mathrm{~nm}$ & $R_{\mathrm{A}}{ }^{\mathrm{II}}$ \\
\hline 0.04 & 379 & 10.02 & 0.823 & 0.758 & $(1.10)$ & $(0.731)$ & $(379.4)$ & $(3.12)$ \\
\hline 0.05 & 260 & 9.40 & 0.778 & 0.378 & 0.535 & 0.353 & 260.8 & 0.592 \\
\hline 0.06 & 159 & 8.58 & 0.742 & 0.282 & 0.539 & 0.354 & 159.7 & 0.374 \\
\hline 0.07 & 173 & 7.46 & 0.731 & 0.330 & 0.602 & 0.397 & 173.7 & 0.476 \\
\hline 0.08 & 170 & 7.41 & 0.695 & 0.321 & 0.674 & 0.444 & 170.7 & 0.455 \\
\hline 0.09 & 151 & 7.05 & 0.654 & 0.294 & 0.735 & 0.484 & 151.7 & 0.398 \\
\hline 0.10 & 119 & 7.33 & 0.571 & 0.295 & 0.913 & 0.601 & 119.5 & 0.400 \\
\hline
\end{tabular}

a Weight fraction of cellulose in cellulose cuprammonium solution; coagulating solution, $w_{\mathrm{Acetone}}: w_{\mathrm{NH}_{3}}: w_{\mathrm{H}_{2} \mathrm{O}}=$ $0.30: 0.0056: 0.6944 ; 298.15 \mathrm{~K}$.

b $d_{\mathrm{PL}}=1.5 \times 10^{3} \mathrm{~kg} \mathrm{~m}^{-3} ; \operatorname{Pr}\left(\mathrm{d}_{1}\right)=\operatorname{Pr}\left(\mathrm{d}_{2}\right)^{\prime}=\operatorname{Pr}\left(\mathrm{d}_{3}\right)^{\prime}=\operatorname{Pr}\left(\mathrm{d}_{4}\right)$; values with parentheses at $w_{\text {Cell }}=0.04$, not adopted in calculations.

c Scanning electron microscopic observation.

d Equation 55.

e Apparent density method (eq 42a).

f Equation 43.

g Equation 44.

h Equation 53.

i Equation 13. 


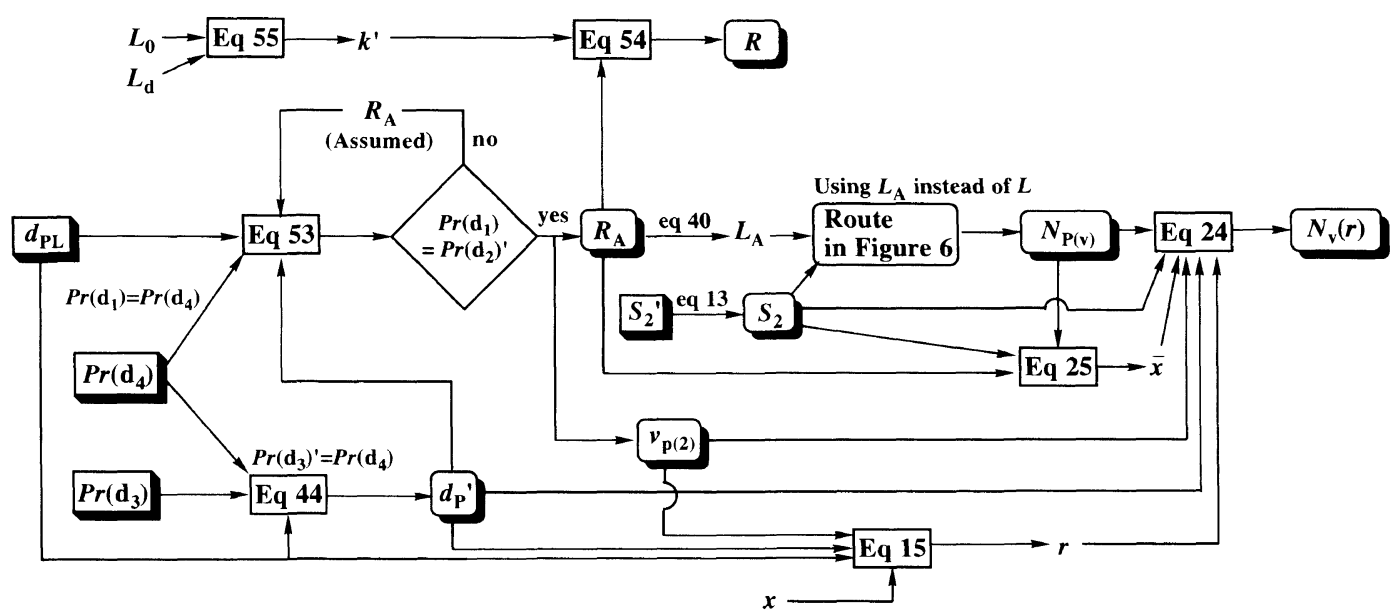

Figure 14. Route of calculation of $R_{\mathrm{A}}, S_{2}, d_{\mathrm{p}}{ }^{\prime}, v_{\mathrm{p}(2)}$, and pore size distribution for vacant-particle pores $N_{\mathrm{v}}(r)$ from $S_{2}{ }^{\prime}, \operatorname{Pr}\left(\mathrm{d}_{3}\right)$, and $\operatorname{Pr}\left(\mathrm{d}_{4}\right)$ evaluated by experiments and $d_{\mathrm{PL}}$.

the new hypothetical planes contract again to give a dry membrane with a thickness of around a few tenth of $L_{0}$ (step $\mathrm{h}$ in Figure 10). In other words, even if we cut off a very thin plane with thickness of $2 S_{2}{ }^{\prime}$ from the bulk dry membrane, the thin plane can never be regarded as a hypothetical plane, in which the phase separation occurred simultaneously under the same conditions.

\section{Comparison of Theory with Experiment}

The theory enables us to predict pore characteristics of membranes on the basis of knowledge on $R_{\mathrm{A}}$ (eq 53), $S_{2}$ (eq 13), $d_{\mathrm{P}}^{\prime}$ (eq 44 ), and $v_{\mathrm{p}(2)}$ (eq 53) under given casting conditions. Table IV collects $S_{2}{ }^{\prime}, \operatorname{Pr}\left(\mathrm{d}_{3}\right)$, and $\operatorname{Pr}\left(\mathrm{d}_{4}\right)$ for membranes prepared under conditions of $w_{\text {Cell }}=0.04$ to 0.10 . By using these values, $d_{\mathrm{P}}{ }^{\prime}$ was obtained by eq 44 and $v_{\mathrm{p}(2)}$ and $R_{\mathrm{A}}$ were determined by eq 53 as summarized in the table. Route of calculation of $R_{\mathrm{A}}, S_{2}$, $d_{\mathrm{P}}{ }^{\prime}$, and $v_{\mathrm{p}(2)}$ and $N_{\mathrm{v}}(r)$ is illustrated in Figure 14 .

With an increase in $w_{\text {Cell }}$, both $\operatorname{Pr}\left(\mathrm{d}_{3}\right)$ and $\operatorname{Pr}\left(\mathrm{d}_{4}\right)$ decreased as expected. Under these preparative conditions, $S_{2}{ }^{\prime}$ decreased with an increase in $w_{\text {Cell }}$. Except for $w_{\text {Cell }}=0.04, d_{\mathrm{P}}{ }^{\prime}$ and $v_{\mathrm{p}(2)}$ were found to increase from 0.535 to 0.910 , and 0.353 to 0.601 , respectively with an increase in $w_{\text {Cell }} . d_{\mathbf{p}}{ }^{\prime}$ for $w_{\text {Cell }}=0.04$ was 1.10 , which did not agree with a tendency observed in cases of $w_{\text {Cell }}$ above 0.05 , i.e., the lower $w_{\text {Cell }}$ is, the larger $d_{\mathbf{P}}{ }^{\prime}$ is. The disparity in $d_{\mathbf{P}}{ }^{\prime}$ at $w_{\text {Cell }}=0.04$ was caused by large $\operatorname{Pr}\left(\mathrm{d}_{4}\right)$. When $w_{\text {Cell }}$ is lower, $R$ becomes larger and accordingly, $R_{\mathrm{A}}$ is also larger. In a case of $w_{\text {Cell }}=0.04$, a part of polymer particles on the surface layer of a membrane can't connect to make a whole body of a network-like structure of the membrane because of larger $R_{\mathrm{A}}$, i.e., $\operatorname{Pr}(\mathrm{GEL})$. Omission of those unconnected polymer particles from the surface layer of the membrane occurs during washing process, resulting in an enlargement of $\operatorname{Pr}\left(\mathrm{d}_{4}\right)$. With an increase in cellulose concentration, $R_{\mathrm{A}}$ decreases gradually and is nearly $1 / 15$ of $R$ because of the collapse of gel layers.

$R$, calculated from $R_{\mathrm{A}}$ and $k^{\prime}$ by eq 54 (see, Figure 14) at $w_{\text {Cell }}=0.05$ to 0.10 as well as $R$, directly determined by phase equilibria experiments under the same conditions as those of casting at $w_{\text {Cell }}=0.04,0.05$, and 0.08 are plotted in Figure 15. In the figure, closed and open circles are calculated and experimental data $\left(R_{\max }\right)$, respectively. Both $R_{\mathrm{s}}$ coincide well and this fact confirms that an effect of collapse during casting process on porosity of a membrane can be reasonably expressed by eq 37. 


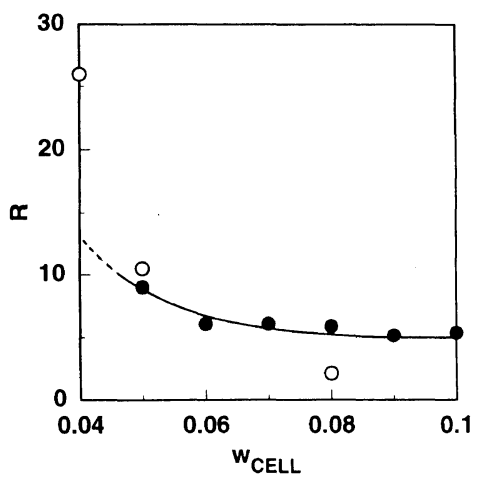

Figure 15. Comparison of $R_{\max }$, evaluated by phase equilibria experiments under the same conditions with those of casting of cuprammonium cellulose membranes with $R$ by eq 54 from $R_{\mathrm{A}}$ and $k^{\prime}$ data: Open circle, $R_{\max }$ by actual phase separation experiment; cellulose cuprammonium solution/acetone-water solution system; $298.15 \mathrm{~K}$; closed circle, $R$ by calculation; values of $k^{\prime}$, $\operatorname{Pr}\left(\mathrm{d}_{3}\right), \operatorname{Pr}\left(\mathrm{d}_{4}\right), d_{\mathrm{p}}{ }^{\prime}, v_{\mathrm{p}(2)}$, and $R_{\mathrm{A}}$ as listed in Table IV are used; $\operatorname{Pr}\left(\mathrm{d}_{1}\right)=\operatorname{Pr}\left(\mathrm{d}_{2}\right)^{\prime}=\operatorname{Pr}\left(\mathrm{d}_{3}\right)^{\prime}=\operatorname{Pr}\left(\mathrm{d}_{4}\right)$.

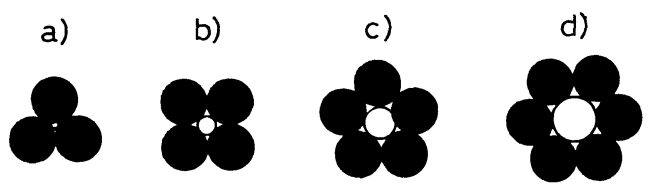

Figure 16. Schematic representation of an inter-polymerparticle pore, a lattice defect and a vacant-particle pore: a), Inter-polymer-particle pore, whose radius is $r_{(\mathrm{i})}$ (eq 33); b), Lattice defect as crevasse made by simultaneous contact of four polymer particles; c), Lattice defect as crevasse made by simultaneous contact of five polymer particles; d), Vacant-particle pore, whose radius is $r_{\min }$ (eq 16).

In this paper, all the pores whose pore radii are smaller than $r_{\min }$ (eq 16) are regarded as inter-polymer-particle pore which is illustrated in Figure 2d or in Figure 16a. $N(r)$ for inter-polymer-particle pores, $N_{\mathrm{i}}(r)$ is given by the $\delta$-function as eq 34 . In an actual membrane there are a lot of small pores whose radii are smaller than $r_{\text {min }}$ and in fact $N(r)$ by EM method $^{5}\left(N(r)_{\mathrm{EM}}\right)$ has a large peak at $r$ between 0 and $r_{\min }$. By introducing the concept of the lattice defect as demonstrated in Figures 16b and $16 \mathrm{c}$, we can improve a theory of $N(r)$ applicable only for vacant-particle pores $\left(r \geq r_{\text {min }}\right)$. Instead, we can rewrite eq 34 in the zero-th approximation as:

$$
N_{\mathrm{i}}(r)=\frac{N_{\mathrm{P}(\mathrm{i})} \delta\left(r-r_{(\mathrm{i})}\right)}{r_{\min }-r_{(\mathrm{i})}} .
$$

Therefore, theoretical $N(r)$ is given as the summation of $N_{\mathrm{v}}(r)$ and $N_{\mathrm{i}}(r)$ :

$$
N(r)=N_{\mathrm{v}}(r)+N_{\mathrm{i}}(r) \text {. }
$$

Here, note that $N_{\mathrm{v}}(r)$ is never overlapped with $N_{\mathrm{i}}(r)$ and we can not always count the number of all inter-polymer-particle pores and even some vacant-particle pores experimentally. Then, $N(r)_{\mathrm{EM}}$ is expected of course less than theoretical $N(r)$.

Figures 17 shows the pore size distribution $N_{\mathrm{v}}(r)$ (full line), calculated by eq 24 using the experimented data in Table IV on $d_{\mathrm{P}}{ }^{\prime}, v_{\mathrm{p}(2)}$, $S_{2}$, and $R_{\mathrm{A}}$, and $N_{\mathrm{i}}(r)$ by eq 56 for membranes prepared under the conditions of $w_{\text {Cell }}=0.05$ to 0.10 . In the figures, $N(r)_{\mathrm{EM}}$ is also shown by open circles. In the range of $c a .0 .1 \mu \mathrm{m}<$ $r<c a .0 .5 \mu \mathrm{m}, N(r)_{\mathrm{EM}}$ is slightly smaller than $N(r)$ and interestingly, in the range of $r<$ $0.1 \mu \mathrm{m}, N_{\mathrm{i}}(r)$ point (closed circle) lies on the lines extrapolated or interpolated by $N(r)_{\mathrm{EM}}$. Figure 17 means that some portion of vacantparticle pores whose $r$ is in the range of 0.1 to $0.5 \mu \mathrm{m}$ can not be accurately counted by EM.

\section{CONCLUSIONS}

(1) Theoretical equations are derived to express the pore size distribution $N(r)$ of vacant-particle pores constituted from vacant particles and inter-polymer-particle pores as crevasses between polymer particles for porous polymeric membranes prepared by the phase separation method.

(2) Pore density for vacant-particle pores $N_{\mathrm{P}}$ can be determined by the theory from twophase volume ratio $R$ and radius of polymer particles $S_{2}$ and thus $N(r)$ is obtained.

(3) As phase separation proceeds in an actual membrane, thickness of a gel membrane decreases, and particle density within a plane increases, resulting in an apparent increase in 
Formation of Porous Polymeric Membrane III
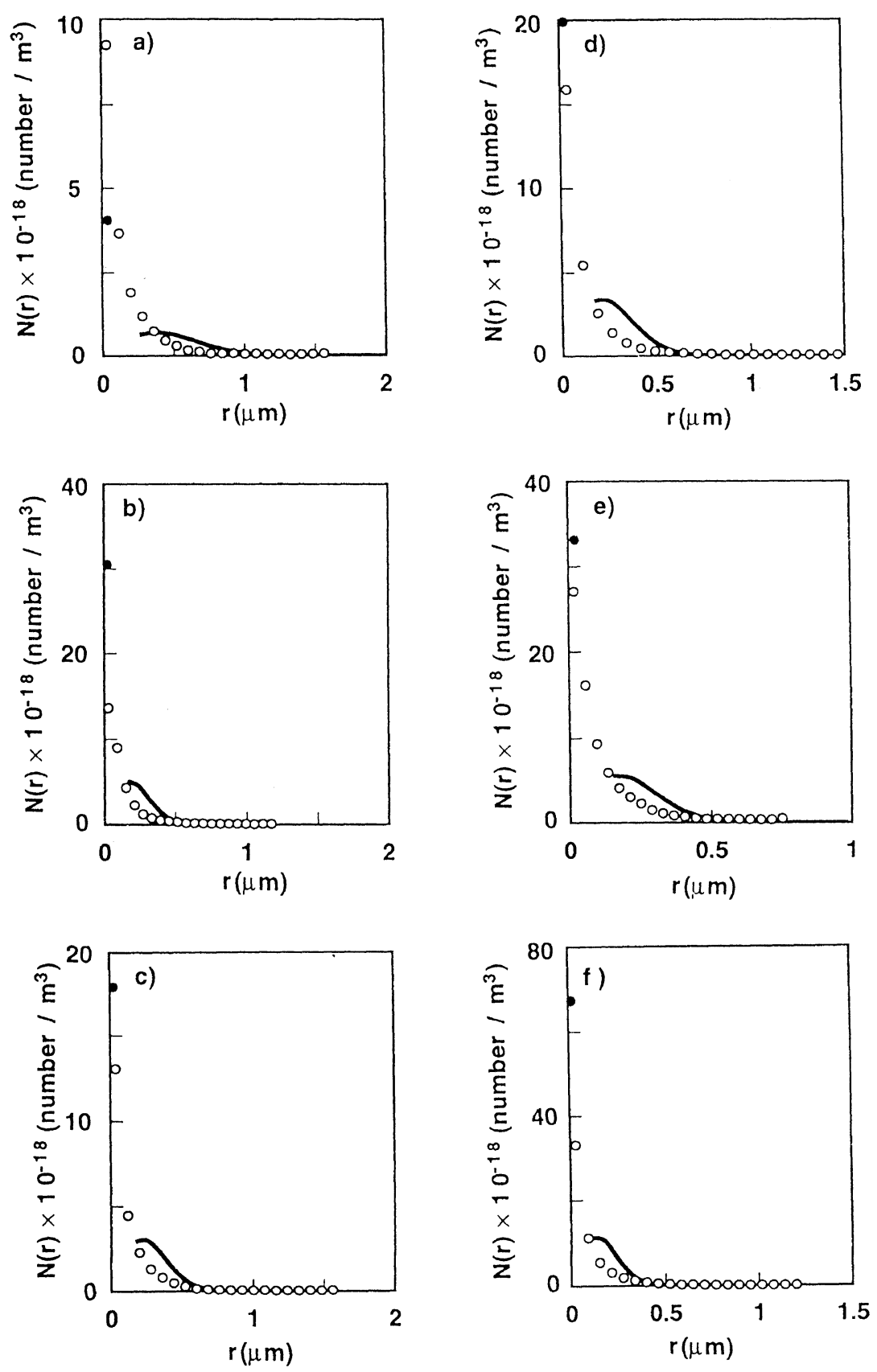

Figure 17. Comparison of experimental pore radius distribution $N(r)$ as determined by EM method with theoretical $N(r)$ : open circle, EM method; full line, $N_{\mathrm{v}}(r)$ (theoretical $N(r)$ for vacant-particle pores; eq $24)$; closed circle; $N_{\mathrm{i}}(r)$ (theoretical $N(r)$ for inter-polymer-particle pore; eq 56); values of $d_{\mathrm{p}}{ }^{\prime}, v_{\mathbf{P}(2)}, S_{2}$, and $R_{\mathrm{A}}$ listed in Table IV are employed; $\left.d_{\mathrm{PL}}, 1.5 \times 10^{3} \mathrm{~kg} \mathrm{~m}^{-3} ; \mathrm{a}\right), w_{\mathrm{Cell}}, 0.05 ; N_{\mathrm{P}(\mathrm{v})}, 3.80 \times 10^{11}$ number m$^{-2}$; b), $w_{\text {Cell }}, 0.06 ; N_{\mathrm{P}(\mathrm{v})}, 1.17 \times 10^{12}$ number $\left.\mathrm{m}^{-2} ; \mathrm{c}\right), w_{\mathrm{Cell}}, 0.07 ; N_{\mathrm{P}(\mathrm{v})}, 9.38 \times 10^{11}$ number $\left.^{-2} ; \mathrm{d}\right), w_{\text {Cell }}$, $0.08 ; N_{\mathrm{P}(\mathrm{v})}, 9.83 \times 10^{11}$ number $\left.\mathrm{m}^{-2} ; \mathrm{e}\right), w_{\text {Cell }}, 0.09 ; N_{\mathrm{P}(\mathrm{v})}, 1.28 \times 10^{12}$ number $\left.^{-2} ; \mathrm{f}\right), w_{\text {Cell }}, 0.10 ; N_{\mathrm{P}(\mathrm{v})}$, $2.06 \times 10^{12}$ number $\mathrm{m}^{-2}$. 
$R$ to $R_{\mathrm{A}}$.

(4) The pore size distribution $N(r)_{\mathrm{s}}$ estimated by EM method were in good agreement with those by the theoretical calculation using $R_{\mathrm{A}}$. We can design or predict pore characteristics of a membrane through use of this theory together with $R_{\mathrm{A}}$ and $S_{2}$.

\section{APPENDIX I}

\section{Derivation of Equation 3}

To find the number of distinguishable arrangements of partitioning balls into boxes, consider the following picture of the 4 balls in the 6 boxes. ${ }^{19}$

\begin{tabular}{|c|c|c|c|c|c|c|c|}
\hline & 0 & & 100 & & 10 & 1 & \\
\hline $\begin{array}{l}\text { Box } \\
\text { number: }\end{array}$ & 1 & 2 & 3 & 4 & 5 & & 6 \\
\hline $\begin{array}{l}\text { Number of } \\
\text { balls: }\end{array}$ & 1 & 0 & 2 & 0 & 1 & & 0 \\
\hline
\end{tabular}

The lines mean the sides of the boxes and the open circles are the balls; note that it requires 7 lines to picture the 6 boxes. This picture shows one of many possible arrangements of the 4 balls in 6 boxes. In any such picture there must be a line at the beginning and at the end, but the rest of the lines ( 5 of them) and the 4 circles can be arranged in any order. Every arrangement of the balls in the boxes can be so pictured. Then the number of ways of partitioning 4 balls into 6 boxes, $W_{6}(4)$ is the number of ways we can select 4 positions for the 4 circles out of 9 positions for 5 lines and 4 circles, ${ }_{9} C_{4}$.

In general, the number of ways, $W_{b}(a)$ of partitioning $a$ balls into $b$ boxes is given by the relation $^{19,20}$

$$
W_{b}(a)={ }_{\{(b-1)+a\}} C_{a}=\frac{\{(b-1)+a\} !}{(b-1) ! a !} .
$$

Note that some boxes may obtain no balls.

When we distribute 10 balls in 6 boxes on condition that each box has at least one ball, the number of such arrangement is just the number of ways of partitioning 4 balls in 6 boxes, $W_{6}(4)$.

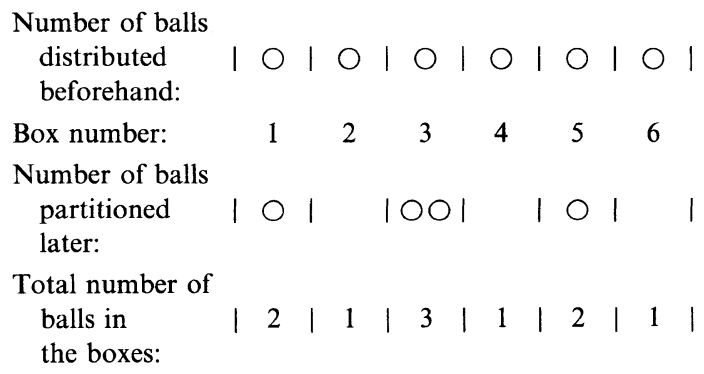

When we distribute $N_{\mathrm{T}} L$ vacant particles into $N_{\mathrm{P}}$ vacant-particle pores, each vacant-particle pore must have at least one vacant particle. Accordingly, the number of ways of partitioning $N_{\mathrm{T}} L$ vacant particles in $N_{\mathrm{P}}$ vacant-particle pores on condition that each pore has at least one vacant particle is just the number of ways of partitioning $\left(N_{\mathrm{T}} L-N_{\mathrm{P}}\right)$ balls in $N_{\mathrm{P}}$ boxes, $W_{N_{\mathrm{P}}}\left(N_{\mathrm{T}} L-N_{\mathrm{P}}\right)$, that is,

$$
\begin{aligned}
& W_{N_{\mathrm{P}}}\left(N_{\mathrm{T}} L-N_{\mathrm{P}}\right) \\
& ={ }_{\left\{\left(N_{\mathrm{P}}-1\right)+\left(N_{\mathrm{T}} L-N_{\mathrm{P}}\right)\right\}} C_{\left(N_{\mathrm{T}} L-N_{\mathrm{P}}\right)} \\
& =\frac{\left\{\left(N_{\mathrm{P}}-1\right)+\left(N_{\mathrm{T}} L-N_{\mathrm{P}}\right)\right\} !}{\left(N_{\mathrm{P}}-1\right) !\left(N_{\mathrm{T}} L-N_{\mathrm{P}}\right) !} .
\end{aligned}
$$

\section{APPENDIX II}

\section{Example of Calculating $P(x)$ by Using Equa- tion 5}

Consider a case of partitioning 5 vacant particles into 3 vacant-particle pores. After distributing one vacant particle to each pore, we can partition the remaining 2 vacant particles into 3 pores in the ways of $W_{3}(2)=6$ :

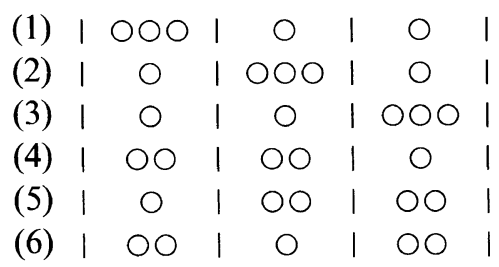

Accordingly, the probability of appearance of the vacant-particle pores with one vacant particle, $P(1)$ is $9 / 18$, i.e., $1 / 2$, and $P(1)$ value calculated by using eq 5 is $W_{2}(2) / W_{3}(2)=1 / 2$. 
On the same ways, $P(2)$ and $P(3)$ can be also calculated by the equation as $W_{2}(1) / W_{3}(2)=$ $1 / 3(=6 / 18)$ and $W_{2}(0) / W_{3}(2)=1 / 6(=3 / 18)$, respectively.

\section{APPENDIX III}

\section{Derivation of Equation 6}

Dividing both numerator and denominator of eq 5 by $N_{\mathrm{T}} L$, we have

$$
\begin{aligned}
P(x) & =\frac{\left(N_{\mathrm{T}} L-N_{\mathrm{P}}\right)\left(N_{\mathrm{T}} L-N_{\mathrm{P}}-1\right) \cdots\left(N_{\mathrm{T}} L-N_{\mathrm{P}}-x+2\right)\left(N_{\mathrm{P}}-1\right)}{\left(N_{\mathrm{T}} L-1\right)\left(N_{\mathrm{T}} L-2\right) \cdots\left(N_{\mathrm{T}} L-x\right)} \\
& =\frac{\left(1-\frac{N_{\mathrm{P}}}{N_{\mathrm{T}} L}\right)\left(1-\frac{N_{\mathrm{P}}}{N_{\mathrm{T}} L}-\frac{1}{N_{\mathrm{T}} L}\right) \cdots\left\{1-\frac{N_{\mathrm{P}}}{N_{\mathrm{T}} L}-\frac{(x-2)}{N_{\mathrm{T}} L}\right\}\left(\frac{N_{\mathrm{P}}}{N_{\mathrm{T}} L}-\frac{1}{N_{\mathrm{T}} L}\right)}{\left(1-\frac{1}{N_{\mathrm{T}} L}\right)\left(1-\frac{2}{N_{\mathrm{T}} L}\right) \cdots\left(1-\frac{x}{N_{\mathrm{T}} L}\right)} .
\end{aligned}
$$

If $N_{\mathrm{T}} L \gg x$ and $N_{\mathrm{P}}<N_{\mathrm{T}} L, P(x)$ can be simplified $\quad N_{\mathrm{P}(\mathrm{v})}$ into

$$
P(x) \cong \frac{\left(1-\frac{N_{\mathrm{P}}}{N_{\mathrm{T}} L}\right)^{x}\left(\frac{N_{\mathrm{P}}}{N_{\mathrm{T}} L}\right)}{\left(1-\frac{N_{\mathrm{P}}}{N_{\mathrm{T}} L}\right)} \cong \frac{\left(1-\frac{N_{\mathrm{P}}}{N_{\mathrm{T}} L}\right)^{x}}{\left(\frac{N_{\mathrm{T}} L}{N_{\mathrm{P}}}-1\right)} .
$$

\section{GLOSSARY OF SYMBOLS}

$L \quad$ volume fraction of polymer-lean

$L_{0} \quad$ thickness of cast solution

$L_{\mathrm{A}}$

$L_{\mathrm{C}, \boldsymbol{i}}$

$L_{\mathrm{d}}$

$L_{\mathrm{g}}$

$L_{i}$

$N_{\mathrm{i}}(r)$

$N_{\mathrm{P}}$

$N_{\mathbf{P}(\mathbf{i})}$ phase

$N_{\mathrm{P}, \text { peak }}^{\prime}$

$N(r)$

$N(r)_{\mathrm{EM}}$

$N_{\mathrm{T}}$

$$
N_{\mathrm{v}}(r)
$$

$N_{\mathrm{v}}\left(r_{\text {peak }}\right)$

$N^{*}\left(r^{*}\right)$

$P_{n}(m)$

mer-lean phase

cut-off length, by pores, of the $i$-th

test line

thickness of dry membrane

thickness of a coagulated gel membrane

length of the $i$-th test lines drawn on a photograph of membrane surface

pore size distribution for interpolymer-particle pores

$\operatorname{Pr}$

$\operatorname{Pr}\left(\mathrm{d}_{1}\right)$

$\operatorname{Pr}\left(\mathrm{d}_{2}\right)$

$\operatorname{Pr}\left(\mathrm{d}_{2}\right)^{\prime}$

$\operatorname{Pr}\left(\mathrm{d}_{3}\right)$

$\operatorname{Pr}\left(\mathrm{d}_{3}\right)^{\prime}$

$\operatorname{Pr}\left(\mathrm{d}_{4}\right)$ unit area of a membrane (= pore density)

number of inter-polymer-particle

pores in unit area of a membrane
$N_{\mathrm{P}}$ theoretically expected for a given combination of $R$ and $S_{2}$ under the random distribution of particles; $N_{\mathrm{P}}$ value which satisfies eq 28 Upper limit of $N_{\mathrm{P}}$ in a case when $N(r)$ has a peak at $r>r_{\min }$ pore size distribution $N(r)$ experimentally determined by the electron micrographic method total number of polymer- and vacant-particles in unit area of a plane

$N(r)$ for vacant-particle pore

value of $N_{\mathrm{v}}(r)$ at $r=r_{\text {peak }}$

$=N_{\mathrm{v}}(r) S_{2} / 2 N_{\mathrm{P}(\mathrm{v})}$

probability that a given polymer particle is surrounded in part by $m$ vacant particles, which belong to $n$ different pores

porosity of a membrane

porosity of dry membrane

porosity of dry membrane

porosity of dry membrane

porosity determined by the apparent density method

real porosity of dry membrane porosity of dry membrane determined from electron micrographs

$\operatorname{Pr}(\mathrm{GEL})$ volume fraction of vacant particles in a gel membrane

$\operatorname{Pr}(\mathrm{PS}) \quad$ volume fraction of a polymer-lean phase in a hypothetical layer at the 


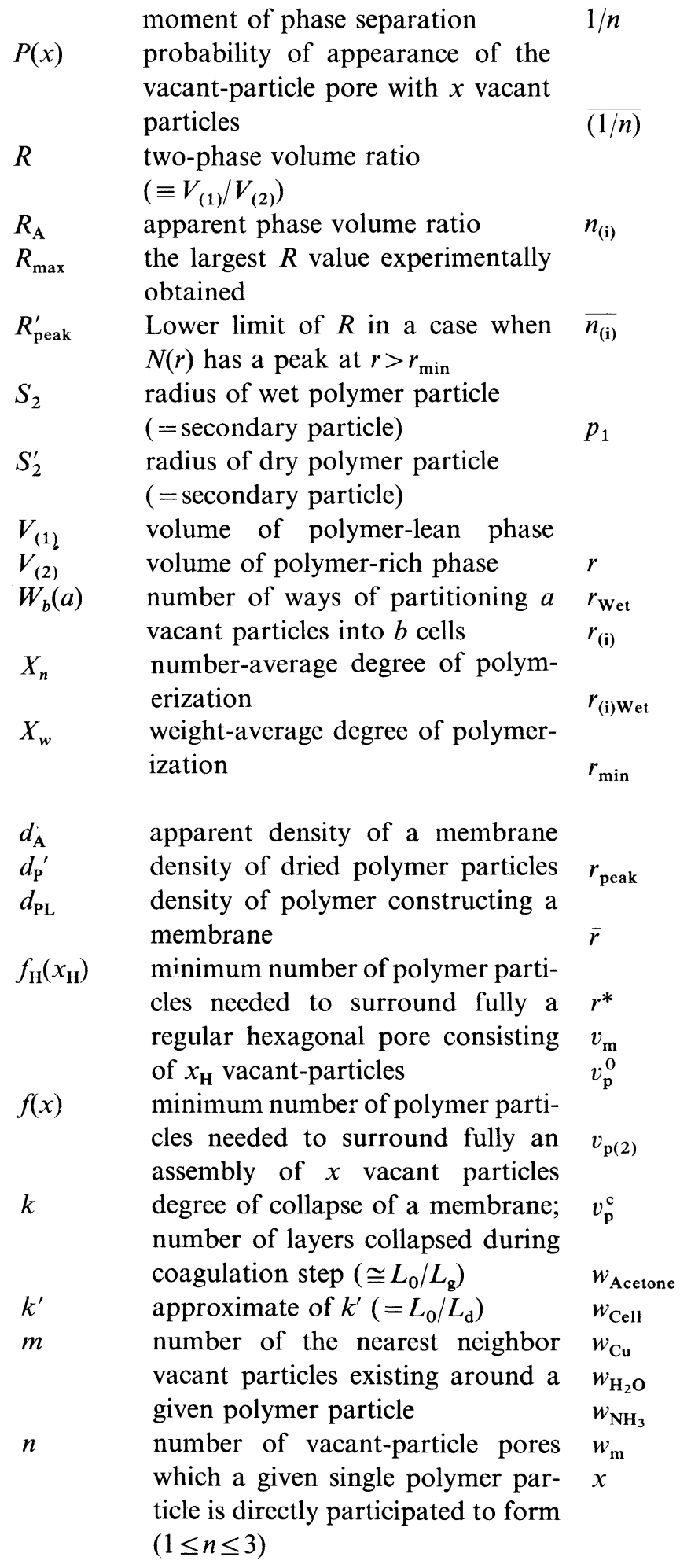

reciprocal $n$; contribution fraction of one polymer particle to the formation of one vacant-particle pore average contribution fraction of one polymer particle to the formation of one vacant-particle pore number of inter-polymer-particle pores directly contacted with a given single polymer particle average number of inter-polymerparticle pores directly contacted with a given single polymer particle 1st order concentration-dependent parameter of thermodynamic interaction parameterxbetween solvent and polymer

pore radius of dry membrane pore radius of wet gel membrane radius of inter-polymer-particle pore of dry membrane radius of inter-polymer-particle pore of wet gel membrane minimum of radius of vacantparticle pore consisting of a single vacant particle

pore radius which gives a peak of $N_{\mathrm{v}}(r)$

average pore radius of dry membrane

$\equiv r / S_{2}$

volume of absolutely dry membrane polymer volume fraction of solution when phase separation occurs polymer volume fraction of polymer rich-phase in equilibrium polymer volume fraction at a critical solution point

weight fraction of acetone

weight fraction of cellulose weight fraction of copper weight fraction of water weight fraction of ammonia weight of absolutely dry membrane number of vacant particles constituting a single vacant-particle pore on the hexagonal lattice sites 


\begin{tabular}{|c|c|}
\hline$x_{\mathrm{H}}$ & $\begin{array}{l}\text { number of vacant particles consti- } \\
\text { tuting a regular hexagonal vacant- } \\
\text { particle pore on the hexagonal lat- } \\
\text { tice sites }\end{array}$ \\
\hline $\bar{x}$ & average $x$ \\
\hline$\chi_{12}{ }^{0}$ & $\begin{array}{l}\text { thermodynamics interaction } \\
\text { parameter between solvent and } \\
\text { nonsolvent }\end{array}$ \\
\hline$\chi_{13}{ }^{0}$ & $\begin{array}{l}\text { thermodynamics interaction } \\
\text { parameter between solvent and } \\
\text { polymer }\end{array}$ \\
\hline$\chi_{23}{ }^{0}$ & $\begin{array}{l}\text { thermodynamics interaction } \\
\text { parameter between nonsolvent and } \\
\text { polymer }\end{array}$ \\
\hline$\delta(r)$ & $\delta$-function \\
\hline$\rho_{\mathrm{p}}$ & $\begin{array}{l}\text { relative amount of polymer precip- } \\
\text { itated }\end{array}$ \\
\hline
\end{tabular}

Acknowledgment. The authors express their sincere gratitude to Miss Miki Inamoto of Fundamental Research Laboratory of Natural \& Synthetic Polymers, Asahi Chemical Industry Co., Ltd. for her technical assistance in EM measurements.

\section{REFERENCES}

1. K. Kamide, H. Iijima, and S. Matsuda, Polym. J., 25, 1113 (1993).

2. K. Kamide, H. Iijima, and H. Shirataki, Polym. J., 26, 21 (1994).

3. K. Kamide, S. Manabe, T. Matsui, T. Sakamoto, and S. Kajita, Koubunshi Ronbunshu, 34, 205 (1977).

4. K. Kamide and S. Manabe in "Materials Science of Synthetic Membranes," D. R. Lloyd, Ed., ACS Symposium Series, No. 269, American Chemical Society, Washington, D.C., 1985, p 197.

5. S. Manabe, Y. Shigemoto, and K. Kamide, Polym. J., 17, 775 (1985).

6. S. Manabe, Y. Kamata, H. Iijima, and K. Kamide, Polym. J., 19, 391 (1987).

7. S. Manabe, H. Iijima, and K. Kamide, Polym. J., 20, 307 (1988).

8. K. Kamide and S. Manabe in "Ultrafiltration Membranes and Applications," Polymer Science and Technology, Vol. 13, A. R. Cooper, Ed., Plenum Press, New York, N. Y., 1980, pp 173-202.

9. K. Kamide and K. Sugamiya, Macromol. Chem., 139, 197 (1970).

10. K. Kamide and K. Sugamiya, Macromol. Chem., 156, 259 (1972).

11. K. Kamide, Y. Miyazaki, and K. Sugamiya, Macromol. Chem., 173, 113 (1973).

12. K. Kamide, K. Yamaguchi, and Y. Miyazaki, Macromol. Chem., 173, 133 (1973).

13. K. Kamide and Y. Miyazaki, Macromol. Chem., 176, 1029 (1975).

14. K. Kamide and Y. Miyazaki, Macromol. Chem., 176, 1051 (1975).

15. K. Kamide, Y. Miyazaki, and T. Abe, Macromol. Chem., 177, 485 (1976).

16. K. Kamide, S. Matsuda, and Y. Miyazaki, Polym. J., 16, 479 (1984).

17. K. Kamide and S. Matsuda, Polym. J., 16, 515 (1984).

18. K. Kamide and S. Matsuda, Polym. J., 16, 591 (1984).

19. M. L. Boas, "Mathematical Methods in the Physical Science," John Wiley \& Sons, Inc., New York, N. Y., 1966, p 693.

20. R. Kubo, "Statistical Mechanics-An advanced Course with Problems and Solutions," NorthHolland Publishing Co., Amsterdam, The Netherlands, 1965, p 36. 